Portland State University

PDXScholar

6-1-1983

\title{
Development of an MMPI Scale to Predict Therapeutic Response to Lithium Carbonate
}

Neal Allen Hayden

Portland State University

Follow this and additional works at: https://pdxscholar.library.pdx.edu/open_access_etds

Part of the Mental and Social Health Commons, and the Psychology Commons Let us know how access to this document benefits you.

\section{Recommended Citation}

Hayden, Neal Allen, "Development of an MMPI Scale to Predict Therapeutic Response to Lithium Carbonate" (1983). Dissertations and Theses. Paper 3322.

https://doi.org/10.15760/etd.3302

This Thesis is brought to you for free and open access. It has been accepted for inclusion in Dissertations and Theses by an authorized administrator of PDXScholar. Please contact us if we can make this document more accessible: pdxscholar@pdx.edu. 
AN ABSTRACT OF THE THESIS OF Neal Allen Hayden for the Master of Science in Psychology presented June 1, 1983.

Title: Development of an MMPI Scale to Predict Therapeutic Response to Lithium Carbonate.

APPROVED BY MEMBERS OF THE THESIS COMMITTEE:

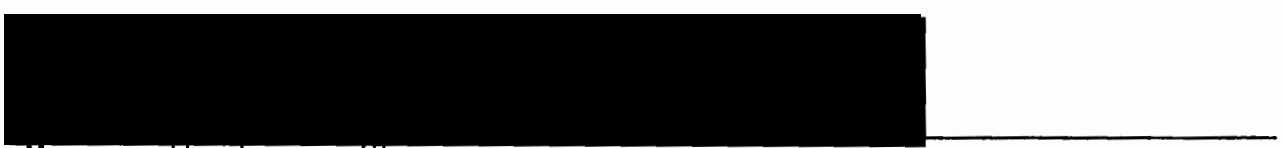
Morris wettman, chatrman
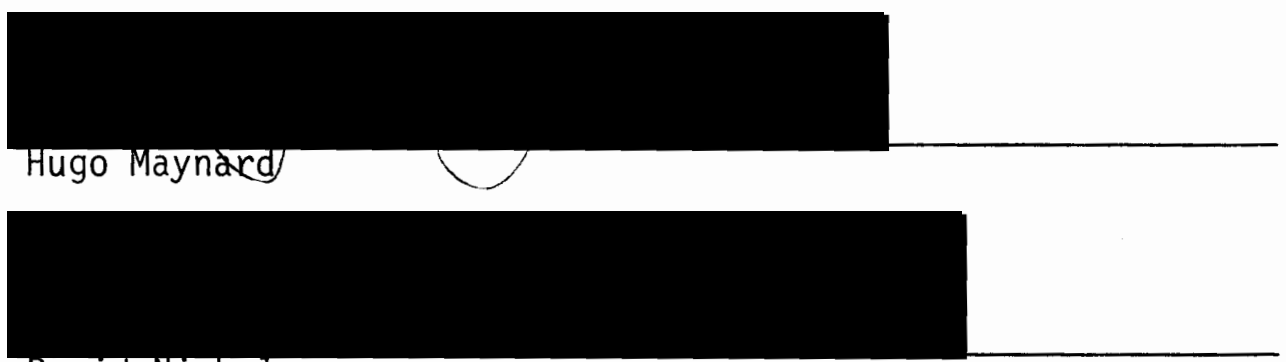

David Nichols

Common medications utilized in the treatment of psychosis include lithium carbonate and the major tranquilizers. The efficacy of lithium is well established in the treatment of manic-depressive patients exhibiting symptoms of mania. The major tranquilizers treat a broader range of psychotic disorders including schizophrenia.

In the treatment of manic-depressive $i 1$ lness, 1 ithium produces normalization of affect with few side effects. However, since the interval between therapeutic and toxic dosages is narrow, lithium treatment must be closely monitored to avoid severe physical problems and even death. When a schizophrenic is incorrectly diagnosed as manic-depressive, and is treated with lithium, the patient does not 
benefit from treatment; this also constitutes an inappropriate risk for lithium toxicity. Conversely, when a manic-depressive is incorrectly diagnosed as schizophrenic and treated with major tranquilizers, the patient benefits only from the sedative effects of these drugs while risking the often debilitating side effects associated with them.

Due to the similarity of their associated symptoms, the diagnostic discrimination of mania and schizophrenia is often difficult. This presents a problem, as diagnoses play an important role in the determination of the treatment of functional psychosis. The difficulty in achieving satisfactory levels of accuracy in diagnosis and subsequent choices of treatment for these two conditions may be due to the subjective nature of behavioral observations and clinical judgments in diagnostic interviews. The hazards of clinical judgment can be reduced through the application of appropriate objective tests.

This research developed a scaie from the Minnesota Multiphasic Personality Inventory (MMPI) item pool which is associated with therapeutic response to 1 ithium carbonate.

Subjects were patients discharged from Dammasch State Hospital from 1973 to 1980 who had at some time during their hospitalization completed the MMPI and were treated with lithium. The criterion group consisted of patients discharged on lithium and the comparison group consisted of patients for whom lithium was discontinued prior to their discharge.

An item analysis of the MMPI compared the response frequencies of the two groups. A chi-square analys is tested for statistical association and 25 items were selected that significantly distinguished the criterion from the comparison group. This 25 item scale had a 
Kuder-Richardson 21 reliability of .75 and it significantly discriminated between lithium responders and lithium nonresponders. 


\title{
DEVELOPMENT OF AN MMPI SCALE TO PREDICT THERAPEUTIC RESPONSE TO LITHIUM CARBONATE
}

\author{
by
}

NEAL ALLEN HAYDEN
A thesis submitted in partial fulfillment of the requirements for the degree of

\author{
MASTER OF SCIENCE \\ in \\ PSYCHOLOGY
}

Portland State University

1983 
TO THE OFFICE OF GRADUATE STUDIES AND RESEARCH:

The members of the Committee approve the thes is of Neal Allen Hayden presented June 1, 1983.

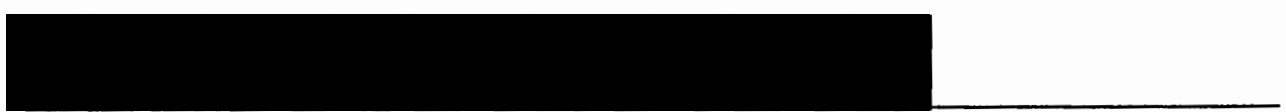

Morris Weitman, Chairman

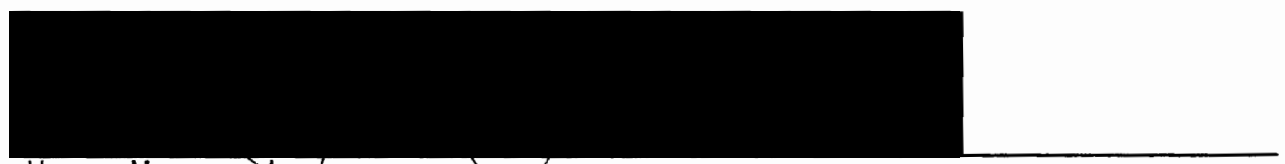

Hugo Maynard

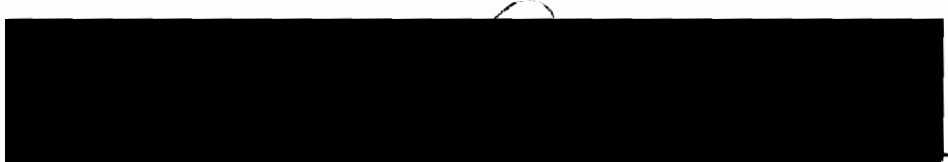

David Nichols

APPROVED:

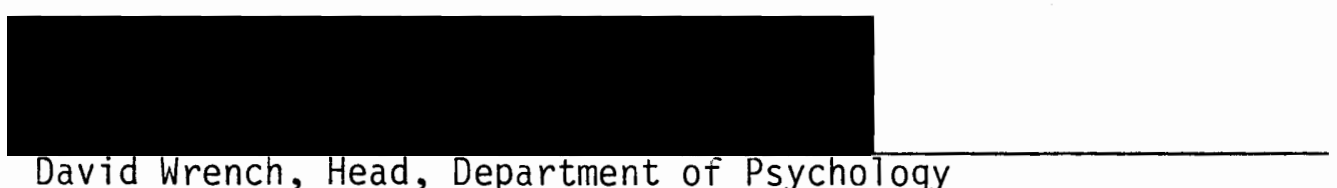

David Wrench, Head, Department of Psychology

Stanley F. Rauch, Deăn of Graduate Studies and Research 


\section{TABLE OF CONTENTS}

PAGE

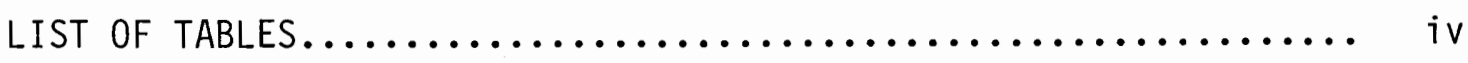
CHAPTER

I INTRODUCTION.................................... 1

I I CHEMOTHERAPY $\ldots \ldots \ldots \ldots \ldots \ldots \ldots \ldots \ldots \ldots \ldots \ldots \ldots \ldots \ldots \ldots$

Major Tranquilizers....................... 4

Mechanism of Action.................... 5

Side Effects........................ 5

Lithium Carbonate....................... 8

Mechanism of Action.................. 10

Side Effects....................... 11

Current Uses....................... 13

Predicting Lithium Response............. 18

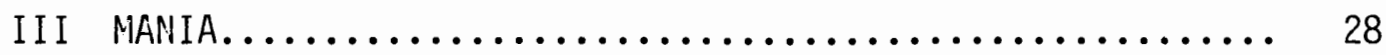

Assessment of Mania...................... 28

IV METHOD.................................... 34

$\checkmark$ RESULTS........................................ 40

VI DISCUSSION.............................. 53

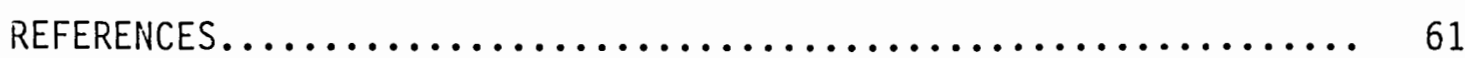

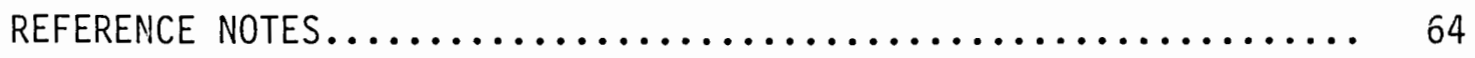

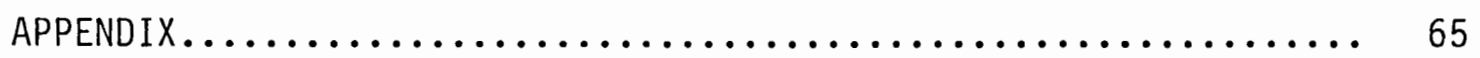


I MMPI SLRS Items and Associated Chi-Square and

Phi Coefficient Values..................... 41

II MMPI LRS Items and Associated Chi-Square and

Phi Coefficient Values...................... 43

II Analysis of Variance for the Lithium Response

Scales................................ 44

IV Cut off Scores and Corresponding True Positive and Negative Values, False Positive and Negative Values, and Hit Rates..................... 45

$V$ Comparing LRS Scores to Elapsed Time in Days

Between MMPI Testing and Initiation of Lithium...... 47

VI Analysis of Variance of Scores of Four MMPI

Clinical Scales............................ 49

VII Pearson Product-Moment Correlation Coefficients

Among the LRS and the MMPI Clinical Scales......... 50

VIII Admitting and Discharge Diagnosis Summary and

$\underline{z}$ Test for Significance of Difference

Between Two Proportions.................... 52 


\section{CHAPTER I}

\section{INTRODUCTION}

Chemotherapy is a major treatment modality for the most severe emotional disorders present today. Major tranquilizers and 1ithium carbonate are two classes of drugs useful in the treatment of various psychotic states. Major tranquilizers are the major treatment for schizophrenia, while lithium carbonate is the most useful agent in the treatment of manic-depressive 111 ness; however, both of these drugs have side effects which can be uncomfortable if not detrimental to the patient. Because major tranquilizers can be both productive and harmful, the physician must be cautious when prescribing these drugs. Differentiating mania from schizophrenia is often an extremely difficult task because the symptoms of these two conditions can be similar. Many manic-depressives are treated as schizophrenics and much time may pass before the correct course of treatment is initiated, resulting in the incorrectly assessed patient possibly being subjected to adverse side effects needlessly. One of the main reasons clinicians misdiagnose manic-depressives is due to the subjective character of the mental status examination. Clinicians assessing patients tend to rely mostly on their judgments rather than objective measures. Since drug selection depends primarily on the diagnosis, an incorrect assessment may lead to an incorrect diagnosis, potentially leading to a suboptimum choice of medication. Great importance is placed upon diagnosis for selection of medication, even though a diagnosis may not be the best 
indicator for determining the selection of medication. Also, to date, there has been minimal research conducted regarding the establishment of objective measures predicting response to lithium treatment.

The widely recognized Minnesota Multiphasic Personality Inventory (MMPI), an objective measure, was utilized in this study for the purpose of developing an objective indicator for drug choice. The MMPI contains 566 statements to which the subject responds, each statement indicating whether or not it is descriptive of self. Sixteen MMPI statements appear twice within the test; this study was not concerned with the 16 repetitions and was concerned with the 550 MMPI items. The purpose of this study was to develop a scale from MMPI items that predict whether or not a patient's symptoms will be controlled by lithium. 
CHAPTER II

\section{CHEMOTHERAPY}

According to Chaplin (1975), chemotherapy is the treatment of mental illness through the use of drugs. Antipsychotic agents, drugs used in the treatment of mental illness, decrease agitation, hostility, and hyperactivity, as well as ameliorate delusions, hallucinations, disordered thoughts and perceptions, emotional and social withdrawal, and paranoid symptoms (AMA Department of Drugs, 1980). Extinguishing or minimizing disturbed behavior by means of antipsychotic drugs allows many patients to participate in individual and group psychotherapy as well as other treatment modalities. Before chemotherapy, such patients would not have been able to take advantage of these programs (Dally, 1967, Holliday, 1965).

According to Martin (1971), once a patient's diagnosis is correctly established, there are four major objectives to be considered in the patient's drug treatment: 1) choice of the most therapeutic medication for the patient; 2) knowledge of synergistic responses to other drugs; 3 ) selection of high quality drugs; 4) making certain that the patient receives medication and responds to the medication in the desired manner.

There are four major categories of psychotropic drugs, they are as follows: anti-anxiety agents, antidepressants, major tranquilizers, and lithium carbonate. The only psychoactive agents this thesis was concerned with were the major tranquilizers and lithium carbonate. 
Major tranquilizers are quite different from lithium. The reasons for focusing on these two types of drugs were that some patients exhibiting certain types of psychotic symptoms may respond favorably to major tranquilizers and other patients exhibiting like symptoms may respond favorably to lithium. The symptoms that these patients exhibit are not always discriminating indicators of sufficient power to determine which drug will be most therapeutic. In many instances, major tranquilizers are utilized when lithium would be the most effective drug and lithium is sometimes used when a major tranquilizer would be the most effective drug. Martin (1971) states that one of four objectives in prescribing medication is choosing the most therapeutic medication for the patient. When treating manic or schizophrenic-like symptoms using lithium or major tranquilizers, the above objective is not always met as well as it should be. The purpose of this research was to develop an MMPI scale that will assist clinicians in identifying patients who may respond to lithium.

\section{MAJOR TRANQUILIZERS}

There are many drugs listed as major tranquilizers and their purpose is for the control of schizophrenia. Thorazine, stelazine, navane and prolixin are only a few of the many major tranquilizers listed in the Physician's Desk Reference (1982). The Physician's Desk Reference (1982, pp. $1637,1810,1815,1856)$ classifies the aforementioned major tranquilizers as indicated "for the management of manifestations of psychotic disorders."

Major tranquilizers are the approved treatment of schizophrenia. A brief example of the types of psychotic symptoms that major 
tranquilizers manage follows: conceptual disorganization, anxiety, tension, hallucinatory behavior, suspiciousness, and blunted affect. According to the AMA Department of Drugs (1980), major tranquilizers are useful in controlling psychotic symptoms, but are not curative.

\section{Mechanism of Action}

It is believed the effectiveness of major tranquilizers, lithium not included, is due to their action upon dopamine. There is a large number of dopamine receptors throughout the brain. Major tranquilizers act to block postsynaptic dopamine receptors found in the mesolimbic and mesocortical systems which are located in the ventral tegmental nucleus. Other sites containing dopamine receptors are the nigroneostriatal and the tuberoinfunibular systems located in the sub nigra (AMA Department of Drugs, 1980, Kvernland, note 2).

Blocking of dopamine receptors located in the ventral tegmental nucleus influences emotional behavior. The exact neurophysiological functions are unclear, but neuroleptic action upon dopamine in the ventral tegmental nucleus controls most primary and secondary symptoms of schizophrenia. Other effects resulting from blocking dopamine receptors in the sub nigra produce extrapyramidal symptoms through secondary anti-adrenergic and anti-cholinergic actions (AMA Department of Drugs, 1980, Kvernland, note 2). These symptoms are commoniy experienced by patients as unpleasant.

\section{Side Effects}

However effective the major tranquilizers are, certain undesirable reactions are reported in the literature. Of primary concern is the extrapyramidal syndrome, a neurotoxic reaction that is one of the side 
effects of the major tranquilizers. This reaction exhibits itself generally as abnormal somatic movements and can sometimes be incorrectly diagnosed as encephalitis, hysteria, tetanus, epilepsy, meningitis, or some other central nervous system disorder. Correctly identified, these side effects may manifest themselves as akathesia, dyskinesia, parkinsonism, and tardive dyskinesia. In akathesia, the patient lacks the control to sit still. Inactivity brings about an overwhelming feeling of uneasiness that causes shifting or tapping of the feet, rocking of the body, or pacing. Akathesia usually appears a few weeks to a few months after therapy has begun (AMA Department of Drugs, 1980, Raskin, 1972).

Dyskinesia normally appears within a few hours to a few days once treatment has been initiated. Abnormal posturing is characteristic of this syndrome producing effects of tetanic spasms which flexes the head and feet backward, involuntary, spasmodic contraction of the mandible, impairment of ability to understand the symbols of language, difficulty in swallowing, and involuntary conjugate upward movement of the eyes. Dyskinesia is frequently followed by an increase of sweat, pallor, fever, and an increase of anxiety (AMA Department of Drugs, 1980). Parkinsonism may begin two weeks to two months after treatment has begun. Parkinsonism is characterized by tremors, rigidity, abnormally slow movement, shuffling gait, postural abnormalities, and excessive secretion of saliva (AMA Department of Drugs, 1980).

Tardive dyskinesia occurs late in treatment, whereas, other side effects may occur immediately after the first administration of the drug. The extrapyramidal syndrome can usually be treated with antiparkinsonian drugs or by withdrawal of the major tranquilizer, 
however, tardive diskinesia occurs late in treatment and often after treatment has been discontinued. These symptoms may last for months or years after the withdrawal of the major tranquilizer (AMA Department of Drugs, 1980).

According to Raskin (1972), the extrapyramidal syndrome can occur in as much as 52 percent of the patients treated with phenothiazines (a major tranquilizer). More recently, the Boston Collaborative Drug Surveillance Program (1973) found that of patients receiving long-term therapy, 21 to 79 percent developed extrapyramidal syndromes. Raskin (1972) cited many associated factors involved in the occurrence of extrapyramidal symptoms. Incidences of akathisia and parkinsonism occurred twice as frequently in females and incidences of dyskinesia were more common in males. Raskin (1972, p. 121) cited:

drug dosage and duration of treatment were related to akathisia, and the individual's threshold was contingent upon his sensitivity to the molecular configuration of the agent used, and its quantity, duration, and rate of increase.

Major tranquilizers have other side effects besides extrapyramidal syndrome symptoms affecting the central nervous system. One such effect is an anti-adrenergic action which may include low blood pressure while in an upright position. Another is an anti-cholinergic effect resulting in such inimical responses as dryness of the mouth, tachycardia, blurred vision, urinary retention, and constipation (AMA Department of Drugs, 1980).

Side effects resulting from treatment with major tranquilizers may produce highly uncomfortable sensations for many patients. Extrapyramidal symptoms may cause anxiety, lack of control of muscular 
movements manifested as painful muscle spasms, difficulty in talking, and excessive salivation. The extrapyramidal syndrome can be a terrifying experience not only for the patient, but for the family as we11.

\section{LITHIUM CARBONATE}

Treatment with lithium carbonate began in 1948 and 1949 in two dissimilar geographical areas. In Australia, John Cade (1949) reported on the use of lithium salts in the treatment of psychotic excitement. Cade reported on ten patients treated with lithium. Three were diagnosed as having chronic mania, while the remaining seven were diagnosed as having recurrent mania. Two of the three chronic cases had been in a state of manic excitement for five years. After the onset of lithium treatment, their symptoms abated. Both were discharged from the hospital and were able to return to home and work. The remaining patient suffering from chronic mania had exhibited a decrease in his excitement state but, because of prior evidence of senility, the patient remained mildly enfeebled and irritable. This patient's treatment with lithium was discontinued. Of the seven patients diagnosed as having recurrent mania, six displayed remission of their manic symptoms after initial treatment with lithium and were able to function as they had before the occurrence of their manic illnesses. The one remaining manic patient was hallucinating, delusional, and in a state of excitement. After treatment with lithium commenced, his excitement was reduced, but the delusional state was unchanged. It must be noted that because the cases were not controlled, the efficacy of lithium in the treatment of mania in 1949 was not clearly established. 
In contrast, Corcoran, Taylor, and Page (1949) reported on a 70 year old woman in the United States who was treated for generalized arteriosclerosis. She was placed on a low sodium diet and was given lithium salts as a substitute for sodium. She was discharged from the hospital and 13 days later passed into a coma and expired. Stern (1949) reported the case of an 82 year old male patient who was brought to the Cedar of Lebanon Hospital, Los Angeles, for convalescence from various physical ailments. The patient was convalescing well. After three days, it was decided to place him on a sodium free diet, substituting Westal, a proprietary drug, for sodium chloride. Westal contained lithium carbonate, citric acid, and potassium iodide, al1 in liquid form. In five days, the patient displayed profound and severe changes. He exhibited symptoms of poisoning including loss of appetite, difficulty in swallowing, decreased heart rate, increased skin sensitivity to stimuli and pain, muscular hyperirritability, rapid contractions of muscles, rapid changes in personality, and mental confusion. All medications were discontinued and the patient recovered within five days. It is the opinion of the researchers that these symptoms were a result of severe poisoning by Westal (Corcoran, Taylor, \& Page, 1949; Stern, 1949).

These were not isolated instances. Hanlon, Romaine, Gilroy, and Deitrick (1949) reported four other cases of lithium carbonate poisoning. In one of the cases the patient died, leading the researchers to suggest that lithium carbonate contributed to, if not actually caused, the patient's death. The other three patients exhibited symptoms of lithium toxicity such as weakness, fatigue, 
blurred vision, tremors, and slurred speech. Once lithium treatments were discontinued, these patients recovered fully.

These cases of lithium poisoning resulted in restrictions of lithium's availability. The New York Times published an article entitled "City Stops the Sale", (February 20, 1949, p. 53), regarding the American Medical Association's indictment of lithium carbonate for four deaths. The Times article stated:

A United States Food and Drug Administration order withdrawing lithium salts from the market and warning a 11 persons who had purchased it "to stop using this dangerous drug at once."

Because of its potential for toxicity, lithium was "withdrawn from the market in the United States and it was not until 1970 that lithium carbonate was approved by the Food and Drug Administration (FDA) for the treatment of acute mania" (Jefferson \& Greist, 1977, pp. xi-xii).

\section{Mechanism of Action}

Lithium is an alkali metal found in trace amounts in the body. The precise mechanism whereby the therapeutic effects of lithium are produced is not known. What is known according to the Physician's Desk Reference (1982, p. 1518) is that:

preclinical studies have shown that lithium alters sodium transport in nerve and muscle cells and effects a shift toward intraneural metabolism of catecholamines, but the specific biochemical mechanism of lithium action in mania is unknown.

According to Baldessarini and Lipinski (1976), lithium is evenly distributed throughout the body fluids, though there is some lag in passing into and out of the brain. Unlike lithium, sodium and potassium ions are differentially distributed throughout the body. One reason for 
this uneven distribution is due to the interior of the axons, which is the part of the neuron that extends away from the cell body and provides the pathway over which signals can travel. The axon holds within it a large concentration of potassium ions and a small concentration of sodium ions. These concentrations are reversed in the body fluids outside the axon (Stevens, 1979). According to Baldessarini and Lipinski (1976, p. 162), the action of lithium:

might help to correct the reported tendency for intracellular sodium concentration to increase in severe affective disorders, although the detailed mechanisms by which lithium might exert a beneficial effect are not clear, and the concept that the distribution of sodium is abnormal in mania and severe depression itself not well established.

Baldessarini and Lipinski (1976) suggest the hypothesis that at optimum doses, lithium can inhibit the release of norepinephrine and dopamine. Kvernland (note 2) is of the opinion that this decrease of norepinephrine at certain receptor sites in the central nervous system may diminish any mood elevating effect. It is further hypothesized, according to Baldessarini and Lipinski (1976, p. 162), that "catecholamines may be functionally overactive in the brain" and that lithium interferes with catecholamine receptor sites.

\section{Side Effects}

Mild neurological side effects of lethargy and feelings of fatigue are often felt at the onset of treatment with lithium which usualiy disappear once the adequate serum levels are obtained (Jefferson \& Greist, 1977). Serum levels refer to the levels of lithium present in the blood. Another side effect may be fine tremor, which is unpredictable in that it may start at the beginning of treatment or 
manifest itself spontaneously at any time during treatment. Fine tremor may persist at therapeutic levels. There is a beta-adrenoceptor blocking agent which aides in reducing fine tremor. This agent, propranolol (Inderal), has not been fully researched, although at the present time it has been found effective in the treatment of fine tremor induced by lithium (Jefferson \& Greist, 1977).

Much more serious neurological side effects resulting from lithium poisoning have now been definitively observed and reported since it was first identified in 1949. The following is a list of the symptoms of lithium toxicity: feelings of fatigue, lethargy, muscle weakness, trembling of the limbs or the entire body, nausea, vomiting, muscular hyperirritability, abnormal response to stimuli, twitching, spontaneous contractions of muscles, incoordination of voluntary movement, coarsening of tremor, difficulty in speaking, lack of coordination due to loss of muscle control, difficulty in concentration, disorientation, confusion, blurred vision, seizures and convulsions, irreversible brain damage, and death (Jefferson \& Greist, 1977). Almost all of these symptoms are dose related and an indication of lithium poisoning.

In conjunction with the mild and serious neurological side effects, lithium has a low therapeutic index; the difference between the dosage needed to reach a desirable effect and the dosage needed to reach a toxic effect may be very small. The dangers of lithium are pointed out in the Physicians Desk Reference (1982, pp. 1518-1519):

lithium toxicity is closely related to serum lithium levels, and can occur at doses close to therapeutic levels. Facilities for prompt and accurate serum determination should be available before initiating therapy.... No specific antidote for lithium is known. 
There seems to be no doubt today that lithium is a valuable drug in the treatment of mania. But its low therapeutic index increases the probability of toxicity; therefore, this potentially dangerous drug should be prescribed and used with great caution.

\section{Current Uses}

Despite indications regarding the efficacy of lithium, the discovery of its toxic effects in 1949 helped to overshadow the emergence of 1ithium as a therapeutic drug. Also, Jefferson and Greist (1970) suggested that the introduction of chlorpromazine (a major tranquilizer) into psychiatry in 1952 delayed the clinical use of lithium. By 1960, more than a decade after its traumatic introduction, some 35 clinical papers were published throughout the world concerning lithium carbonate; however, no paper was written in the United States until 1966 (Gattozzi, 1970).

Schlagenhauf, Tupin and White (1966, p. 201) pioneered the research in the United States with their paper "The Use of Lithium Carbonate in the Treatment of Manic Psychosis." Their results indicated that all patients they studied who were treated with lithium responded favorably. Extensive research accumulated through the sixties on lithium and its effects on mania. Through the works of Johnson, Gershon and Hekimian (1968), Baastrup and Schou (1967), Baastrup and Schou (1968) and others, the pharmacological rehabilitative effects became widely known.

The accumulated works of Schou and Baastrup also documented prophylactic effects of lithium carbonate using naturalistic designs. The subjects in their studies were patients that had experienced 
recurrent manic-depressive episodes. The researchers compared frequency of episodes of $i l l n e s s$ prior to, during and after lithium treatment. Prior to lithium treatment, patients were in a psychotic state due to their illness, with the average duration of psychotic states being 13 weeks per year. The states would occur on the average of every eight months. During lithium maintenance, the average length of the psychotic episode was two weeks, occurring on the average of once every 60 to 85 months (Davis, 1976). But the most noteworthy clinical tests were conducted by Johnson et al. (1968). They researched iithium in the treatment of manic states using a double blind trial with chlorpromazine and lithium. Forty-two subjects were selected from patients admitted to Bellevue Psychiatric Hospital or from direct referrals. The authors do not indicate the number of subjects that had been admitted to Bellevue, where and how the referrals were made, or whether the subjects were selected randomly. Johnson et al. (1968, p. 563) report simply that "patients considered suitable were selected" as the only criterion for selection. Patients were diagnosed as manic or schizo-affective from the assessments of three psychiatrists. The researchers do not indicate if the psychiatrists were blind to the study nor do they indicate if measures of reliability among the psychiatrists were attempted. As cited by the researchers, diagnoses were based on the criteria listed in Mayer-Gross (1960). Twenty-seven patients were diagnosed manic-depressive, manic phase, one patient as chronic mania and 14 patients as schizo-affective. Subjects were admitted to a research ward and all previous medications were discontinued except for chloral hydrate or paraldehyde which were used for sedation. The patients also were placed on a placebo for a baseline period averaging five days. 
Upon administration of the treatment drugs, patients were assigned randomly to either lithium or chlorpromazine conditions and dosages were increased for each patient until a therapeutic response or manifestations of toxicity occurred. Clinical assessments were gathered at weekly intervals. Patients were rated by two psychiatrists using the Brief Psychiatric Rating Scale (BPRS) and Treatment Response Assessment Method (TRAM) (Johnson et al., 1968). Correlations between the two psychiatrists were not reported. A psychologist administered a structured Clinical Interview (Johnson et al., 1968) at baseline, three to five days, 10 to 12 days and 16 to 18 days of treatment. The Wittenborn scale was filled out weekly by the resident and the nursing staff filled out the Nurses Observational Scale for Inpatient Evaluation (NOSIE) and Ward Behavior Inventory (WBI). References were not listed for the residents or nursing staff's scales nor were correlations between nursing staff reported, however, the authors refer to a later review for a more detailed analysis of the ratings. All staff completing scales were unaware of the correct medications. Although Johnson et al. (1968) did not state how these various scales were utilized to make a final clinical assessment, these researchers reported that 78 percent of the manics treated with lithium carbonate exhibited complete or nearly complete remission. Thirty-six percent of the manics treated with chlorpromazine exhibited compiete or nearly complete remission. The condition of 85 percent of the schizo-affective patients treated with lithium deteriorated. The symptoms in the remaining schizo-affective patients treated with chlorpromazine showed no significant change. These authors did not state what or if any further statistical analyses were performed and they did not report levels of 
significance regarding their findings. Nevertheless, Johnson et al. (1968, pp. 568, 571) stated that the results:

show unequivocally the superior therapeutic efficacy of lithium carbonate in manic states.... Significant differences were noted between the two drugs in quality of action. Both agents produced a reduction in overactivity but in optimum doses chlorpromazine tended to produce sluggishness. Lithium produced normalization of affect and ideation; the action of chlorpromazine on affect and ideation was less consistent, less clear and slower in onset.

The researchers seemed to suggest that though both agents produce a reduction in overactivity, the effects of lithium carbonate in this area lean toward more normalization of affect.

Other than the works just mentioned, there have been few controlled studies researching lithium in the treatment of mania. Beside the ethical issue of withholding medication which could ultimately reestabiish a patient's mental stability, controlled studies can be dangerous. There have been some experimental studies using placebo groups, but these studies have been discouraged because some patients in placebo groups have committed suicide (Davis, 1976). With the several studies researching lithium using placebo, Davis (1976) calculated the statistical significance of the correlations between the variables in each study. Davis $(1976$, p. 3 ) concluded that:

the empirical data clearly show that lithium has quite a substantial prophylactic effect, one that is highly significant $\left(p=10^{-86}\right)$ and one that is consistently demonstrated in all studies. These conclusions are reinforced by the fact that several studies were collaborative and multi-institutional and consistently demonstrated the lithium effect in the different institutions. 
Lithium has been used for the treatment of many disorders both medical and psychiatric. Jefferson and Greist (1977, p. 4) list many disorders for which lithium has been utilized. They are as follows:

manic-depressive illness, depression, schizo-
affective disorder, schizophrenia, premenstrual
tension, self-mutilation, childhood behavior
disorders, mental retardation, paranoia,
catatonia, phobia, hyperthyroidism, obsessive
compulsive personality, granulocytopenia,
Meniere's disease, drug abuse, inappropriate
ADH secretion, spasmodic torticollis, tardive
dyskinesia, painful shoulder syndrome,
Parkinson's disease, ulcerative colitis,
epilepsy, thyroid malignancy, organic brain
syndrome, Gilles de la Tourette and Huntington's
chorea.

These disorders are not a complete list of all the disorders lithium has been used for, nor is the therapeutic value established for lithium in all of these conditions. As must be apparent, lithium is a relatively new drug; it was approved by the FDA for the treatment of acute mania only ten years ago, and in 1974 it was approved for prophylaxis of recurrent manic episodes. Pharmacists receive printed inserts (note 1) with lithium carbonate supplies published according to FDA guidelines stating that "maintenance therapy prevents or diminishes the intensity of subsequent episodes in those manic-depressive patients with a history of Mania."

Manic-depressive illness (bipolar disorder, Diagnostic Statistical Manual: III) is a disorder characterized by symptoms of either mania or depression. Lithium is effective in the treatment of manic-depressive illness, mania type, however, its effectiveness in the treatment of the depressive phase is not clearly understood. According to the Task Force On Lithium Therapy (1975, p. 998), lithium has also shown evidence of 
effectiveness against unipolar depression, however, the Task Force stated that:

the inexactness of the definitions of unipolar

illness and the relatively small number of patients studies to date indicate the need for additional evaluation in this disorder.... At this time, experimental results are not sufficiently conclusive to permit a clear definition of the value of lithium in acute depression.

Lithium has not to date been approved by the FDA for the treatment of acute depression or for prophylaxis against unipolar depression.

\section{Predicting Lithium Response}

Steinbook and Chapman (1970) attempted to find characteristics among inpatients at the Henry Phipps Psychiatric Clinic which would correlate with response to lithium. Newly admitted patients were screened by a resident physician and his/her supervisor during a one year period. The researchers do not indicate the year, the number of patients screened, the number of patients admitted or what sort of maladies brought the patients to the hospital. Of those screened, 32 patients were given lithium treatment and selected as subjects for research. Criteria for prescribing lithium were not detailed. All subjects were administered the MMPI at the beginning of their hospitalization. Three subjects were eliminated from the experimental sample because their MMPI profiles exhibited random sorts, all true or false response sets, or incompletion. Twenty-two subjects were given a final diagnosis of manic-depressive, manic type, three subjects schizo-affective, three schizophrenic, with one other. The 29 subjects were treated for a minimum of one month with lithium, achieving therapeutic blood levels. Major tranquilizers were prescribed after two 
weeks if no significant improvement was observed. Nursing staff recorded ward behavior on a 55 item behavioral chart. The authors did not indicate where or how this chart was developed. Seventeen items were selected from the 55 items as "1ithium-responsive targeted symptoms" (Steinbook \& Chapman, 1970, p. 525). These items were similar to items reported by Bunney, Goodwin, Davis and Fawcett (Steinbook \& Chapman, 1970) and were charted daily for each patient. This information was evaluated by two psychiatrists who independently rated it on an eight point scale. Inter-rater reliability was high $(r=0.90$; $p<0.01)$. Fifteen subjects were found to have improved with 1ithium. It is unclear from the authors' description whether the information gathered from the two psychiatrists was used to prescribe the major tranquilizers and/or to determine response or nonresponse to lithium. In Steinbook and Chapman's (1970) study, a correlational matrix was utilized including the following scales: MMPI validity and clinical scales, Edwards' SD (social desirability), Schaffer's Ac (acquiescence), Block's EC-5 (ego control) and Welsh's factor scales A and R (anxiety and repression). Also included in the correlational matrix were Peterson's six signs of psychosis, Benarick's items, and subject's age, sex, weight, maximum lithium blood level and diagnosis (Steinbook \& Chapman, 1970). Multiple linear regression was employed to evaluate each variable's contribution to lithium response. There was no significant correlation between lithium response and age, weight, maximum lithium blood level or diagnosis. There was a significant correlation between lithium response and sex, with males responding to lithium more frequently than females. Benarick's items and Peterson's signs were unrelated to lithium response. MMPI scales that were 
associated with lithium response are listed in the following descending order of significance: Ac, Ma, K, F and R. Results of a multiple Iinear regression analysis found that AC accounted for 35 percent of the variance and that Ma contributed seven percent of the variance. Scales $K, F$ and $R$ did not add significantly to the variance. The authors concluded that the Ac scale was "the best correlate of response to 1ithium" (Steinbook \& Chapman, 1970, p. 529).

Ananth, Engelsmann and Kiriakos (1980) attempted to determine the value of the MMPI scales as predictors of 1 ithium response. Subjects were outpatients selected from two Montreal psychiatric hospitals. Ananth et a1. (1980, p. 151) stated "59 outpatients (26 males and 33 females) were consecutively selected for the study", but they did not indicate if this was the total number of outpatients treated at the clinics. All patients selected for study suffered from a bipolar affective disorder. The only other information regarding diagnosis was "the group of nonresponders suffered an average of 1.2 manic and 1.3 depressive episodes after 1ithium therapy" (Ananth et al. 1980, p. 152). Patients were not included in the study if their lithium blood levels were inadequate, or if they suffered from a physical illness. Forty of the 59 patients were selected as subjects, 28 as responders and 12 as nonresponders. Responders were those patients who for the past two years had functioned at premorbid levels with lithium therapy. Nonresponders were those patients who had a psychotic episode during the past two years of lithium treatment and required neuroleptics other than 1ithium. All subjects were administered the MMPI once the study began. The authors did not indicate how diagnoses were made, how the patients were monitored to determine if they were functioning at premorbid 
levels, or why the nonresponders were treated with lithium. The authors did not indicate if the subjects' outpatient clinic appointments were standardized nor did they indicate if nonresponders were hospitalized during episodes of psychosis. Ananth, et al. (1980) stated that nonresponders scored higher on scales four, six and nine (Psychopatic Deviate, Paranoia and Mania), while responders scored higher on scales one, seven and ten (Hypochondriasis, Psychasthenia and Social Introversion). Upon further analysis, none of these tendencies were found to be statistically significant.

House and Martin (1975) attempted to develop a sign for predicting nonresponse to lithium in depressed patients. Twenty-six patients were diagnosed as having an affective disorder, depressed type according to the criteria of Winokur and Clayton (House \& Martin, 1975) were inpatients at the National Institute of Mental Health and were utilized as subjects. House and Martin (1975) did not indicate how patients were referred to the Institute, nor did they indicate how many patients were screened. At the time of admission to the program, a psychiatrist and a social worker, who were members of the research staff, interviewed the patients, collected information from the family, other hospitals, previous physicians and conducted psychological testing all for the purpose of establishing diagnoses. Within the first week of hospitalization, subjects were given the MMPI. During this period, the subjects were medication free. Lithium and a placebo were administered on a double blind basis. Placebo periods lasted for six days and lithium treatments lasted for 12 days. During lithium treatments, lithium serum levels were established. The Bunney-Hamburg Scale (House \& Martin, 1975) was utilized for establishing a mean depression rating 
for each subject. The authors did not indicate who administered the tests and whether the testers were unaware of the subjects' medication and diagnosis. Each subject's mean depression rating for the first five days before lithium treatment was compared with his/her mean depression rating during the last five days of lithium treatment. Measured differences from these two ratings determined if subjects improved or did not improve. Those who improved were responders and those who did not were nonresponders. None of the subjects exhibited any symptoms of mania during the research. On the basis of their MMPI profiles, the 26 subjects were divided into two groups. Twenty-one subjects had scales two and seven (Depression and Psychasthenia) greater than $T$ scores of 70 , and these scales were among the top four ranked scales. Five subjects had scales two and seven lower than $T$ scores of 70 , with neither scale being among the top four ranked scales. Seventeen of the high two-seven group were responders and all five of the low two-seven group were nonresponders, these results were statistically significant. The authors stress the importance of the low two-seven group for the purpose of predicting those patients who would not respond to lithium. House and Martin (1975, p. 646) reported:

in our experience, most depressed patients have high two-seven profiles. A high two-seven group may therefore be quite heterogeneous and may include subgroups refractory as well as responsive to lithium carbonate.... There is evidence that lithium carbonate is an effective antidepressant for at least some depressed patients. The MMPI may prove to be a usefur tool in delineating a nonresponsive subgroup of patients.

Donnelly, Goodwin, Waldman and Murphy (1978) compared the MMPI validity scales, ten clinical scales, 52 special scales and an item 
analysis of the 566 MMPI items for the purpose of predicting lithium response. Fifty-three subjects were selected from patients hospitalized at the National Institute of Mental Health, Bethesda, Maryland. Prior to hospitalization, the criteria from Feighner et al. (Donnelly et al., 1978) was utilized to screen all patients for a primary affective disorder. The authors do not indicate how many patients were screened or admitted. All subject were hospitalized for a major depressive episode according to the criteria of Feighner et al. (Donnelly et al., 1978). A11 subjects were administered a placebo for the first five days of treatment and then lithium for the next 28 days. Staff who were involved with the subjects' treatment and subsequent ratings were blind to the medication schedule. Subjects were rated by the nursing staff twice daily for depression from a scale drived from Murphy, Miller, Alterman and Weingartner (Donnelly et al., 1978). The interrater reliability correlation coefficient was .77 . At the end of the lithium treatment period a statistical analysis was utilized to determine from the ratings if subjects' depressive symptoms improved (responders) or did not improve (nonresponders). The ratings yielded 29 responders and 24 nonresponders. Upon analysis of the 65 MMPI scale scores, 11 showed significant differences between responders and nonresponders. Ten of these scales according to Donnelly et al. (1978, p. 554) "were no better than chance in predictive value" and only the Eo scale (ego overcontrol) correctly differentiated responders from nonresponders. The authors did not give any further information as to why the ten scales "were no better than chance". The Ac scale which was noted as significant in Steinbook and Chapman's (1970) study was reported by Donnelly et al. (1978, p. 555) as "not a good predictor" of lithium response. Donnelly 
et al. (1978) reported similar trends to those House and Martin published. For example, they reported seven of eleven nonresponders with low two-seven profiles and twenty of thirty-two responders with high two-seven profiles. Ten subjects had neither high nor low two-seven profiles. These trends, al though similar to prior research, were not statistically significant.

Donnelly et a1. (1978) also conducted an item analysis of the 566 MMPI items. Subjects were randomly assigned to two groups. Group A consisted of 15 responders and 12 nonresponders. Group B consisted of 14 responders and 12 nonresponders. Group A was utilized to derive a scale empirically from an item analysis of the MMPI. Group B was utilized to differentiate responders from nonresponders using scores derived from group A. For the item analysis, items were ranked according to how many responders and nonresponders they correctly identified. According to Donnelly et al. (1978, p. 553):

the best combination of MMPI items was determined by working from the highest to the lowest ranked items, using the best combination of two MMPI items at a time, then the best of three items, then four and so on, until the optimum number and combination of items were determined. The next step involved the determination of the weights assigned to responses on these items, with the most highly discriminating items being assigned higher weights.

Nine items were established for predicting lithium response in males with 100 percent accuracy and nine items were established for predicting lithium response in females with 89 percent accuracy. From the results of a cross validation procedure the authors reported a 100 percent agreement. This study does not indicate values of statistical significance. Donnelly et a1. (1978, p. 556) stated that their scale 
offers a "promising alternative to the theoretical-rational approach of predicting response to antidepressant drugs based on pretreatment depressive symptoms."

Burdick and Holmes (1980) investigated the ability of the MMPI scales, developed by Donnelly et a1. (1978), to predict antidepressant responses in an outpatient sample of 20. Subjects were selected from patients in treatment at an outpatient clinic. How patients were referred to this clinic was not indicated. The subjects were diagnosed as having some form of a major affective disorder and had histories of at least one hospitalization for affective disorders. Subjects had been treated with lithium for at least six weeks with the longest period being six years. The MMPI was administered at varying times for each subject with all subjects having completed it within 12 months after being treated with lithium. Ten subjects had been responsive to lithium, seven females and three males. Ten subjects had not been responsive to lithium, eight females and two males. The authors did not indicate if the subjects were randomly selected, the population size from which the subjects came, how the diagnoses were made and what the diagnoses were. The criteria for determining responders and nonresponders were based on the clinical judgment of a psychiatrist. The psychiatrist continuousiy prescribed lithium to subjects who in his/her clinical judgment benefitted from lithium; thus they were categorized as responders. For subjects who did not respond to lithium the psychiatrist would proceed to an alternate treatment, thus these were categorized as nonresponders. The authors did not indicate any further information regarding the alternate treatments. Burdick and Holmes (1980) compared the Donnelly et al. (1978) Lithium Response 
Scale-Male and Lithium Response Scale-Female to their two groups of 20 subjects. Comparison of the scale score means using t-tests for the responders and nonresponders yielded no significant differences according to t-test scores. Further statistical analysis did not significantly differentiate between responders and nonresponders for either the male or female Lithium Response Scales. The authors concluded that these scales poorly predict lithium response.

A brief review of the five studies, previously mentioned, produces disparate results. Steinbook and Chapman (1970) selected subjects who were inpatients being treated with Tithium. Most of the subjects were given a discharge diagnosis of manic depressive, manic type. They found the MMPI scale Ac as the best significant indicator associated with lithium response.

Ananth et al. (1980) utilized outpatients suffering from a bipolar affective disorder to determine the usefulness of the MMPI clinical scales as predictors of lithium response. There is some indication from the authors that their subjects suffered from manic and/or depressive episodes. The authors reported that they found no significant difference between lithium responders and non-responders.

Subjects in House and Martin's (1975) study were inpatients suffering from an affective disorder, depressive type. House and Martin (1975) reported that high two-seven profiles were significantly associated with response to lithium and low two-seven profiles were significantly associated with non-response to lithium.

Donnelly et al. (1978) utilized only inpatients hospitalized for a depressive episode. The authors reported similar high and low two-seven 
profile trends as House and Martin (1975) had. However, Donnelly et al. (1978) found these trends statistically nonsignificant.

In comparing the scales studies by Steinbook and Chapman (1970), Donnelly et al. (1978) reported that MMPI scale Eo significantly differentiated responders from non-responders and that MMPI scale Ac was not significant. The authors found contradicting results between their research and Steinbook and Chapman's (1970) study. They failed to mention that their subjects exhibited depressive symptoms while Steinbook and Chapman (1970) subjects exhibited manic symptoms. Thus, the subjects may not be comparable. Donnelly et al. (1978) developed two scales, one for females and another for males to predict antidepressant response to lithium.

Burdick and Holms (1980) studied the Donnelly et al. scales utilizing outpatients suffering from an affective disorder. Mood and affect were not indicated. The authors found the scales to be unreliable in predicting response to lithium. Their study did not replicate the Donnelly et al. (1978) study since one study utilized inpatients and the other outpatients.

Four out of the five studies previously mentioned utilized subjects exhibiting depressive symptoms and, according to previous research, lithium's effectiveness with unipolar depression is questionable. None of the studies support each other and it is questionable whether any of these studies have developed a reliable tool for predicting lithium response. These studies have illuminated the enigmatic problem of developing such a tool. At the present time, only a few researchers have attempted to address this issue. 


\section{CHAPTER III}

\section{MANIA}

Manic depressive $i 11$ ness is characterized by severe mood disorder and sometimes accompanied by secondary thought disturbance (Cohen, 1975). There are three stages of mania according to Carlson and Goodwin (1973) and Cohen (1975). Stage One is the hypomania stage in which the mood is elevated but unstable, thoughts are somewhat tangential and there is an increase of motor activity. During the hypomania stage, the manic may laugh more than usual, be slightly more irritable, exhibit a lack of concentration and be hyperverbal. Stage Two is the acute mania stage. All symptoms and abnormalities found in Stage One are exhibited in Stage Two, except that they are more intense as well as more disturbing to others. The manic is hyperverbal, grandiose, lacks discretion, has flight of ideas, loss of contact with reality, angry outbursts and is increasingly labile. Stage Three, delirious mania stage, the manic in this stage exhibits bizarre psychomotor behavior. He or she is hyperverbal, labile, suspicious, disoriented, unable to complete a thought and exhibits constant motor activity. Hallucinations and delusions are common and the manic at this stage may be incontinent of urine and feces.

\section{ASSESSMENT OF MANIA}

The phenomena of mania are generally clinically differentiable from other psychiatric maladies; however, during the manic phase of 
manic-depressive illness, schizophrenic-like symptoms may arise and increase the difficulty of making a correct diagnosis. Murphy, Goodwin and Bunney (1975) found delusions occurring in approximately one-half of all manic episodes. It also has been found that ideas of reference (false beliefs, i.e. being spied upon), grandiosity, confusion, persecutory and other paranoid thinking also may manifest during mania. The above symptoms are very similar to the manifestations exhibited by schizophrenics, resulting in many clinicians mistakenly diagnosing manics as schizophrenics.

An important instance in which the diagnostic procedure can result in the inclusion of manic cases among schizophrenic cases has been illustrated in the work of Carpenter and Straus (1973). They investigated Schneider's first-rank symptoms (FRSs), which was considered an accepted objective measure for diagnosing schizophrenia until recently. According to Carpenter and Straus (1973, p. 847), FRSs had received "widespread attention in German-speaking countries, Scandinavia, England and other parts of the world." According to Carpenter and Straus (1973), Schneider's system for diagnosing schizophrenia by identifying symptoms was developed for establishing diagnostic clarity, which would improve the clinicians' ability to identify patients suffering from schizophrenia. According to Carpenter and Straus (1973), Schneider attempted to identify symptoms which can be observed by clinicians and these symptoms were assumed to occur only in schizophrenics. A brief description of the FRSs according to Carpenter and Straus (1973) reveals 11 first-rank symptoms and a patient with one or more of these symptoms present is considered schizophrenic. Carpenter and Straus (1973) investigated the utility of Schneider's FRSS 
in the context of the International Pilot Study of Schizophrenia (IPSS). At the time of the Carpenter and Straus (1973) study, the IPSS had been located in nine countries with a collective sample size of 1,202 patients. Carpenter and Straus (1973) selected 131 subjects from the IPSSs United States pool of subjects. The 131 subjects had been recently admitted to one of three psychiatric hospitals located in Prince George County, Maryland and, at the time of admission, exhibited delusions, hallucinations, inappropriate or bizarre behavior, gross psychomotor disorder, social withdrawal, thinking disorder, overwhelming fear, disorder of affect, depersonalization, self-neglect or a diagnosis of psychosis. To insure a large enough representation of affective illness, 34 patients suffering from an affective disorder, from the Clinical Center at the National Institute of Health (CCNIH) were included with the original 131 patients. The CCNIH had been studying these patients for manic-depressive illness. The authors did not indicate how the IPSS or the CCNIH obtained and screened their subjects. Interviews were conducted by one of two psychiatrists within eight days of admissions. Interviews involved open-ended questioning, a thorough investigation of the presenting pathology and a rating of observed behavior. Further information was collected by way of Psychiatric History Schedules and Social Description Schedules. The authors did not indicate who interviewed the patients to obtain the data for the two schedules. For further details regarding the interview process and the two schedules, the authors referred to the World Health Organization (1973). The data collected from subjects were utilized to determine if any of the 11 FRSs were present. Of the 131 IPSS subjects, 101 were diagnosed as schizophrenics, 12 as having affective psychosis and 18 as 
having neurotic or character disorder. Of the 34 CCNIH subjects, 27 were diagnosed as having an affective psychosis, five as having neurotic or character disorder and two as having schizophrenia. These diagnoses were obtained from the psychiatrist's diagnostic judgment. With the IPSS and CCNIH subjects combined, the FRSs correctly identified only 51 percent of the schizophrenic group. The FRSs identified 23 percent of the affective disorder group and nine percent of the neurotic and character disorder group as schizophrenic. The FRSs significantly identified a greater proportion of the schizophrenic group compared to the affective psychosis group. However, according to Carpenter and Straus (1973, p. 847, 851):

taken together, these symptoms which he
[Schneider] considers pathognomonic of
schizophrenia occur in one fourth of the
manic-depressive patients. Therefore,
Schneider's system for identifying
schizophrenia, while highly discriminating,
leads to significant diagnostic errors if FRS
are regarded as pathognomonic... Therefore, we
conclude that the postulated pathognomonicity of
FRSs is refuted. It appears that using the rule
that the presence of any one FRS is sufficient
to diagnose schizophrenia would lead to
substantial misclassification.

Carpenter and Straus' (1973) research demonstrates the difficulty in discriminating schizophrenia from mania. Even with the use of objective measures, researchers were unable to distinguish reliably between the two disorders.

It has long been recognized that to differentialiy diagnose schizophrenia and manic-depressive disorder on the basis of acute symptoms alone is an exquisitely difficult task (Procci, 1976).

Although difficult, it is important to diagnose differentially between mania and schizophrenia so that correct treatment can be 
implemented. Before the advent of lithium therapy, phenothiazines were among the few pharmacological agents available. According to Murphy et a1. (1975), the general anti-psychotic characteristics of phenothiazines contributed to a lower diagnostic frequency of manic-depressive $i 11$ ness prior to the advent of lithium. Previously, clinicians found no value in differentially diagnosing mania from schizophrenia since treatment was similar. However, once lithium was marketed, the reported incidence of mania increased (Murphy et al., 1975).

Despite the recent increase in the diagnosis of mania, some researchers suggest that theoretically and statistically, this increase should be even higher. Abrams, Taylor and Gaztanaga (1974, p. 640) have proposed that further research into schizophrenia would yield a "high proportion of patients suffering from affective $i 11$ ness." In the above study, Abrams et al. (1974) found that 50 percent of the paranoid schizophrenics in their study satisfied their research criterion for mania, yet it is not mentioned whether or not these patients would have responded to lithium treatment. This study does suggest that there are many manic-depressive patients mistakenly diagnosed as paranoid schizophrenics, and even though there is an increase in the reported incidence of mania, there may be many more cases of mania that are misdiagnosed.

Diagnoses are many times utilized for the selection of medication, although they may not be a reliable indicator for determining the selection of medication. It has been found that many patients may not be diagnosed as manic depressive when this would be their correct diagnosis. This suggests that the use of diagnoses for prescribing medications is not accurate. This present research conducted an item 
analysis of the MMPI to develop a scale to predict those patients who would respond to lithium. An MMPI scale predicting lithium response will allow clinicians to utilize an objective test for the purpose of predicting lithium response. Subjects were selected from patients who were treated as inpatients at Dammasch State Hospital, Wilsonville, Oregon. 


\title{
CHAPTER IV
}

\author{
METHOD
}

Subjects who were selected for study had been inpatients at Dammasch State Hospital, Wilsonville, Oregon from 1973 to 1980. Dammasch is a state mental hospital serving the Portland metropolitan area and surrounding counties, providing treatment exclusively for psychiatric disorders. From 1973 to $1980,23,852$ patients were admitted and 23,833 were discharged from Dammasch. Approximately 60 percent of these patients were voluntary and 40 percent were involuntarily committed to the hospital. Maximum bed capacity at Dammasch was approximately 460 beds.

On entering the hospital, potential patients were screened by a physician. As a result of this screening the potential patient was or was not admitted. A person was not admitted for a variety of reasons such as the person changed their mind or the physician prescribed outpatient treatment. Patients admitted were assigned an admitting diagnosis by the screening physician, assigned to a treatment team and possibly prescribed medication.

The treatment team consisted of the patient's physician, psychologist, social worker, nurse, psychiatric aide and other personnel involved in the patient's treatment. Members of the treatment team offer input regarding the patient's psychological behavior. The physician processes the information from the treatment team meetings and makes a decision as to what treatments to implement. Treatments may 
consist of group therapy, industrial therapy, occupational therapy, recreational therapy, chemotherapy, et cetera. Chemotherapy is the treatment modality with which this study is concerned. The specific pharmacological agent this study is concerned with is lithium carbonate. There are several criteria which clinicians apply when considering the prescription of lithium; these criteria are as follows:

1) Prior successful treatment with lithium

2) Familial response to lithium

3) Lack of therapeutic response to other drugs

4) Manic symptoms

5) Depressive symptoms

The patient's past history is important in developing individual treatment plans. If the patient has been on lithium prior to their most recent admission, attention will be on: how long the patient had been on lithium; what sort of behaviors the patient exhibited before and during lithium treatment; how long ago, if at all, did the patient discontinue lithium prior to the present admission; other pertinent information. Clinicians assess the immediate family members' psychiatric history. If an immediate member of the patient's family had been or is being treated with lithium, then lithium treatment for the patient may be indicated. If a patient has not responded favorably to other psychotropic medications, then the clinician may choose to initiate a trial treatment of lithium. Other reasons for initiating lithium treatment include the patient exhibiting manic or depressive symptoms. If lithium therapy is initiated and the patient benefits from lithium, then the patient most likely will be discharged with a prescription for lithium carbonate. 
The decision to discontinue lithium may be made in the same manner as its prescription. The physician makes the decision to discontinue treatment by the information given in treatment team meetings. The reason for discontinuing lithium may be because the patient exhibited no therapeutic response to the treatment. If lithium has no effect, it will be discontinued and other pharmaceutical agents may be prescribed. If the patient clearly has not benefited from lithium, then the patient will not be discharged with a prescription for lithium. When discharged, it is the physician's responsibility to assign a discharge diagnosis. Every patient is given a discharge diagnosis regardless of treatment received.

The treatment team was also responsible for referring the patient for psychological testing. Not all patients received psychological testing, the reasons are as follows: patients resistive to testing, lack of time to administer the test, physician deemed the testing would be non-beneficial to the patient's treatment, or the patient has had psychological testing completed during a previous Dammasch admission. Only patients who were administered the MMPI during the same hospitalization they were treated with lithium were utilized as subjects for this research.

Prior to collecting data from Dammasch for this study, a research proposal was submitted to the Research Committee at Dammasch. This committee recommended to the clinical director at Dammasch that this study be approved as it meets their research criteria, does not violate patient confidentiality and respects human rights. Approval to conduct research was granted by the clinical director of Dammasch. 
A11 patients who were admitted to Dammasch from 1973 to 1980 were potential subjects for this research. The first step in selecting subjects was to select all patients who had completed the MMPI. The Psychology Department at Dammasch kept records of the psychological tests administered to patients from 1973 to 1980. Approximately 2,000 patients were administered the MMPI during this period. Each of these patients had an MMPI answer sheet and an MMPI profile stored in a file at the Dammasch Psychology Department. Each individual profile was examined and MMPI scores exhibiting either random sorts, all true or false response sets or gross incompletion were eliminated from the study.

The next step was to compare the nearly 2,000 patients identified as having appropriate MMPI profiles with their charts stored in the Medical Records Department at Dammasch. The charts contained medication sheets, physician orders, discharge summaries, admission and discharge dates, age, sex, and the physician's diagnoses based upon the second edition of the Diagnostic Statistical Manual (DSM II). Medication sheets in each chart were perused in order to determine if the patient ever had been prescribed lithium. All patients prescribed lithium during the same hospitalization they were administered and satisfactorily completed the MMPI were accepted as subjects for this research. For the period 1973 to 1980 , a total of 179 patients met these criteria.

The criterion group was comprised of 130 subjects who were treated with lithium and discharged with a prescription for lithium. Subjects in the criterion group were regarded as lithium responders. The comparison group was comprised of 49 subjects who were treated with 
lithium, but not so discharged. Subjects in the comparison group were regarded as lithium nonresponders. The treatment groups were as follows:

Group One: Lithium responders. Patients who were treated with lithium carbonate while in the hospital and discharged from the hospital with a prescription for lithium.

Group Two: Lithium nonresponders. Patients who were treated with lithium carbonate while in the hospital, but discharged without a prescription for lithium.

The following information was entered on seven computer cards for each subject: 566 MMPI item responses, lithium responder or lithium nonresponder, admission and discharge dates, date prescribed lithium, date completed MMPI, age, sex, discharge diagnoses and hospital identification number. For each individual MMPI item, the responses of the comparison and criterion groups were compared. Originally, the design specified utilization of a validation generalization (Clopton, 1978). This approach requires random bifurcation of both the comparison and criterion groups to produce two sets of criterion and comparison groups. However, the comparison group of 49 subjects was too small in size to divide; therefore, only the criterion group of 130 subjects was bifurcated. Each criterion group was comprised of 65 subjects who were randomly selected by a random numbers table. For each MMPI item, responses of the two criterion groups, separately, were compared with the responses of the one comparison group; a $2 \times 2$ chi-square analysis 
was employed. Use of the validation generalization sharply reduces the probability of an item reaching statistical significance by chance alone. 


\section{CHAPTER $V$}

\section{RESULTS}

The number of hospital days for the 179 subjects in this study ranged from 14 to 492 with a mean of 79 days. One hundred thirty subjects were lithium responders and the remaining 49 were lithium nonresponders. Most of the physicians' discharge summaries documented the subjects' response or nonresponse to lithium. Two nonresponders developed adverse side effects causing the physicians to discontinue lithium treatment, though the physicians indicated lithium had been efficacious. One nonresponder developed adverse side effects and lithium was discontinued with no indication of lithium's efficacy. Another subject refused lithium after several weeks of treatment; though treatment was discontinued, the physician indicated that the subject had improved during lithium treatment. All four of these subjects were assigned to the nonresponder group.

An item analysis of the MMPI was employed with chi-square comparisons of item endorsement rates of responders and nonresponders. The group of nonresponders was divided into two subgroups; each of these groups were compared with the group of nonresponders. Thus, for each MMPI item, there were two chi-square values. One of these chi-square analyses compared a criterion subgroup with the comparison group and the other chi-square analysis compared the other criterion subgroup with the comparison group. MMPI items with both chi-square values significant at the .05 level or better $x^{2}$ $(1)=3.8, \underline{p}<.05$ were selected for 
further study. Table I, Small Lithium Response Scale (SLRS) lists 19 items with chi-square values of 3.8 or greater. Item numbers 8 and 318 are identical; item 318 was, therefore, omitted from further study.

\section{TABLE I}

MMPI SLRS ITEMS AND ASSOCIATED CHI-SQUARE

AND PHI COEFFICIENT VALUES *

\begin{tabular}{|c|c|c|c|c|c|}
\hline $\begin{array}{l}\text { MMPI item } \\
\text { number }\end{array}$ & $\begin{array}{c}\text { chi- } \\
\text { square }\end{array}$ & phi & $\begin{array}{c}\text { MMPI item } \\
\text { number }\end{array}$ & $\begin{array}{c}\text { chi- } \\
\text { square }\end{array}$ & phi \\
\hline 2) & $\begin{array}{l}7.49 \\
7.49\end{array}$ & $\begin{array}{l}.26 \\
.26\end{array}$ & 231) & $\begin{array}{r}13.99 \\
5.87\end{array}$ & $\begin{array}{l}.35 \\
.23\end{array}$ \\
\hline 7) & $\begin{array}{l}6.11 \\
5.00\end{array}$ & $\begin{array}{l}.23 \\
.21\end{array}$ & 258) & $\begin{array}{l}5.61 \\
4.00\end{array}$ & $\begin{array}{l}.22 \\
.19\end{array}$ \\
\hline 8) & $\begin{array}{l}5.60 \\
4.06\end{array}$ & $\begin{array}{l}.22 \\
.19\end{array}$ & 283) & $\begin{array}{l}9.45 \\
5.45\end{array}$ & $\begin{array}{l}.29 \\
.22\end{array}$ \\
\hline 81) & $\begin{array}{l}7.28 \\
6.32\end{array}$ & $\begin{array}{l}.25 \\
.23\end{array}$ & $312)^{\star \star}$ & $\begin{array}{l}4.73 \\
4.73\end{array}$ & $\begin{array}{l}.20 \\
.20\end{array}$ \\
\hline 103$)^{\star *}$ & $\begin{array}{l}5.37 \\
4.65\end{array}$ & $\begin{array}{l}.22 \\
.20\end{array}$ & 313) & $\begin{array}{l}4.13 \\
4.13\end{array}$ & $\begin{array}{l}.19 \\
.19\end{array}$ \\
\hline 143) & $\begin{array}{l}4.93 \\
4.56\end{array}$ & $\begin{array}{l}.21 \\
.20\end{array}$ & 399) & $\begin{array}{l}4.88 \\
4.13\end{array}$ & $\begin{array}{l}.21 \\
.19\end{array}$ \\
\hline 160) & $\begin{array}{r}10.50 \\
6.12\end{array}$ & $\begin{array}{l}.30 \\
.23\end{array}$ & 407) & $\begin{array}{l}6.37 \\
3.83\end{array}$ & $\begin{array}{l}.24 \\
.18\end{array}$ \\
\hline 165) & $\begin{array}{l}5.00 \\
4.23\end{array}$ & $\begin{array}{l}.21 \\
.19\end{array}$ & 537) & $\begin{array}{l}6.11 \\
6.91\end{array}$ & $\begin{array}{l}.23 \\
.25\end{array}$ \\
\hline 168$)^{\star \star}$ & $\begin{array}{l}6.94 \\
4.34\end{array}$ & $\begin{array}{l}.25 \\
.20\end{array}$ & 561) & $\begin{array}{r}9.71 \\
11.38\end{array}$ & $\begin{array}{l}.30 \\
.32\end{array}$ \\
\hline 228) & $\begin{array}{l}3.82 \\
8.31\end{array}$ & $\begin{array}{l}.18 \\
.27\end{array}$ & & & \\
\hline
\end{tabular}

\footnotetext{
A11 calculations based on responses of 114 subjects.

Items were answered false.
} 
As the number of items in the SLRS is increased, the reliability should be increased proportionally to the square root of the number of items contained within the scale (Matheson, Bruce \& Beauchamp, 1974, p. 38). To increase the number of items within the scale, one of each of the item's chi-square values was allowed to fall as low as 3.39. This value is approximately half way between the .05 and the .10 level of significance. The other value was required to equal or exceed 3.8 as noted previously. It was hoped that by relaxing the requirements for the inclusion of items on the SLRS, a somewhat larger scale could be developed with enhanced reliability characteristics. As a result of this relaxation procedure, six additional items were added to the SLRS. This new scale, the Lithium Response Scale (LRS) is presented in Table II.

Reliability of the SLRS and the LRS were estimated utilizing the Kuder Richardson Formula 21. This analysis yielded coefficients of .68 for the SLRS and .75 for the LRS; the longer LRS was noticeably more reliable than the SLRS.

A standard one-way analysis of variance was utilized to determine the significance of the difference in mean scale scores between responders and nonresponders to lithium. This analysis measured the ability of the SLRS and the LRS to separate the two groups. As shown in Table III, the SLRS and the LRS significantly differentiated lithium responders from nonresponders. 
TABLE I I

MMPI LRS ITEMS AND ASSOCIATED CHI-SQUARE

AND PHI COEFFICIENT VALUES *

\begin{tabular}{|c|c|c|c|c|c|}
\hline $\begin{array}{l}\text { MMPI item } \\
\text { number }\end{array}$ & $\begin{array}{c}\text { chi- } \\
\text { square }\end{array}$ & phi & $\begin{array}{c}\text { MMPI item } \\
\text { number }\end{array}$ & $\begin{array}{c}\text { chi- } \\
\text { square }\end{array}$ & phi \\
\hline 2) & $\begin{array}{l}7.49 \\
7.49\end{array}$ & $\begin{array}{l}.26 \\
.26\end{array}$ & 219) & $\begin{array}{l}3.48 \\
4.12\end{array}$ & $\begin{array}{l}.17 \\
.19\end{array}$ \\
\hline 3) & $\begin{array}{l}4.29 \\
3.37\end{array}$ & $\begin{array}{l}.19 \\
.17\end{array}$ & 228) & $\begin{array}{l}3.82 \\
8.31\end{array}$ & $\begin{array}{l}.18 \\
.27\end{array}$ \\
\hline 7) & $\begin{array}{l}6.11 \\
5.00\end{array}$ & $\begin{array}{l}.23 \\
.21\end{array}$ & 231) & $\begin{array}{r}13.99 \\
5.87\end{array}$ & $\begin{array}{l}.35 \\
.23\end{array}$ \\
\hline 8) & $\begin{array}{l}5.60 \\
4.06\end{array}$ & $\begin{array}{l}.22 \\
.19\end{array}$ & 258) & $\begin{array}{l}5.61 \\
4.00\end{array}$ & $\begin{array}{l}.22 \\
.19\end{array}$ \\
\hline 11) & $\begin{array}{l}4.19 \\
3.29\end{array}$ & $\begin{array}{l}.19 \\
.17\end{array}$ & 283) & $\begin{array}{l}9.45 \\
5.45\end{array}$ & $\begin{array}{l}.29 \\
.22\end{array}$ \\
\hline 81) & $\begin{array}{l}7.28 \\
6.32\end{array}$ & $\begin{array}{l}.25 \\
.23\end{array}$ & $312)^{\star \star}$ & $\begin{array}{l}4.73 \\
4.73\end{array}$ & $\begin{array}{l}.20 \\
.20\end{array}$ \\
\hline 99) & $\begin{array}{l}5.35 \\
3.29\end{array}$ & $\begin{array}{l}.22 \\
.17\end{array}$ & 313) & $\begin{array}{l}4.13 \\
4.13\end{array}$ & $\begin{array}{l}.19 \\
.19\end{array}$ \\
\hline 103$)^{\star \star}$ & $\begin{array}{l}5.37 \\
4.65\end{array}$ & $\begin{array}{l}.22 \\
.20\end{array}$ & 399) & $\begin{array}{l}4.88 \\
4.13\end{array}$ & $\begin{array}{l}.21 \\
.19\end{array}$ \\
\hline 143) & $\begin{array}{l}4.93 \\
4.56\end{array}$ & $\begin{array}{l}.21 \\
.20\end{array}$ & 407) & $\begin{array}{l}6.37 \\
3.83\end{array}$ & $\begin{array}{l}.24 \\
.18\end{array}$ \\
\hline 147) & $\begin{array}{l}3.40 \\
4.06\end{array}$ & $\begin{array}{l}.17 \\
.19\end{array}$ & 483) & $\begin{array}{r}3.58 \\
13.32\end{array}$ & $\begin{array}{l}.18 \\
.35\end{array}$ \\
\hline 160) & $\begin{array}{r}10.50 \\
6.12\end{array}$ & $\begin{array}{l}.30 \\
.23\end{array}$ & 537) & $\begin{array}{l}6.11 \\
6.91\end{array}$ & $\begin{array}{l}.23 \\
.25\end{array}$ \\
\hline 165) & $\begin{array}{l}5.00 \\
4.23\end{array}$ & $\begin{array}{l}.21 \\
.19\end{array}$ & 561) & $\begin{array}{r}9.71 \\
11.38\end{array}$ & $\begin{array}{l}.30 \\
.32\end{array}$ \\
\hline 168$)^{\star \star}$ & $\begin{array}{l}6.94 \\
4.34\end{array}$ & $\begin{array}{l}.25 \\
.20\end{array}$ & & & \\
\hline
\end{tabular}

A11 calculations based on responses of 114 subjects.

Items were answered false. 
TABLE II I

ANALYSIS OF VARIANCE FOR THE

LITHIUM RESPONSE SCALES

SLRS

\begin{tabular}{|c|c|c|c|}
\hline Source & Mean & $\begin{array}{l}\text { Standard } \\
\text { Deviation }\end{array}$ & $\underline{F}$ \\
\hline responders $(n=130)$ & 13.9 & 2.7 & \\
\hline
\end{tabular}

$65.00 \quad .001$

nonresponders $(n=49) \quad 9.3 \quad 3.7$

LRS

responders $(n=130) \quad 17.4 \quad 3.7$

$66.35 \quad .001$

nonresponders $(n=49) \quad 12.2 \quad 4.0$

Table IV lists individual LRS score values, their corresponding true positive and true negative values, false positive and false negative values and hit rate values. True positive values represent those subjects who were lithium responders and were predicted to be lithium responders. True negative values represent those subjects who were lithium nonresponders and were predicted to be lithium nonresponders. False positive values represent those subjects who were lithium nonresponders and were predicted to be lithium responders. False negative values represent those subjects who were lithium responders and were predicted to be lithium nonresponders. The hit rate values were derived by adding the number of true positive and true negative values and dividing the sum by the total number of subjects. These hit rate values helped to establish an optimal cutting score for 
TABLE IV

CUT OFF SCORES AND CORRESPONDING TRUE POSITIVE AND NECATIVE VALUES, FALSE POSITIVE AND NECATIVE VALUES,

AND HIT RATES

\begin{tabular}{|c|c|c|c|c|c|}
\hline $\begin{array}{l}\text { CUT } \\
\text { OFF } \\
\text { SCORES } \\
\end{array}$ & $\begin{array}{l}\text { CUMULATIVE } \\
\text { TRUE } \\
\text { POSITIVES } \\
\end{array}$ & $\begin{array}{l}\text { CUMULATIVE } \\
\text { TRUE } \\
\text { NECATIVES } \\
\end{array}$ & $\begin{array}{l}\text { CUMULATIVE } \\
\text { FALSE } \\
\text { POSITIVES } \\
\end{array}$ & $\begin{array}{l}\text { CUMULATIVE } \\
\text { FALSE } \\
\text { NECATIVES } \\
\end{array}$ & $\begin{array}{l}\text { HIT } \\
\text { RATE }\end{array}$ \\
\hline 4 & 130 & 2 & 47 & 0 & .74 \\
\hline 5 & 130 & 2 & 47 & 0 & .74 \\
\hline 6 & 130 & 2 & 47 & 0 & .74 \\
\hline 7 & 130 & 7 & 42 & 0 & .76 \\
\hline 8 & 130 & 9 & 40 & 0 & .78 \\
\hline 9 & 130 & 13 & 36 & 0 & .80 \\
\hline 10 & 129 & 18 & 31 & 1 & .82 \\
\hline 11 & 126 & 22 & 27 & 4 & .83 \\
\hline 12 & 120 & 32 & 17 & 10 & .85 \\
\hline 13 & 116 & 32 & 17 & 14 & .83 \\
\hline 14 & 108 & 37 & 12 & 22 & .81 \\
\hline 15 & 96 & 38 & 11 & 34 & .75 \\
\hline 16 & 87 & 42 & 7 & 43 & .72 \\
\hline 17 & 82 & 43 & 6 & 48 & .70 \\
\hline 18 & 65 & 44 & 5 & 65 & .60 \\
\hline 19 & 59 & 45 & 4 & 71 & .58 \\
\hline 20 & 47 & 46 & 3 & 83 & .52 \\
\hline 21 & 32 & 48 & 1 & 98 & .45 \\
\hline 22 & 19 & 49 & 0 & 111 & .38 \\
\hline 23 & 8 & 49 & 0 & 122 & .32 \\
\hline 24 & 1 & 49 & 0 & 129 & .28 \\
\hline 25 & 0 & 49 & 0 & 130 & .27 \\
\hline
\end{tabular}

Values correspond to related cut off score values and higher. Calculations based on 130 subjects.

Values correspond to related cut off score values and lower. Calculations based on 49 subjects.

*** Values correspond to related cut off score values. Calculations based on 179 subjects. 
the LRS. For each scale score value, a proportion is listed representing the number of responders identified at that cut-off score. As shown in Table IV, the hit rate values increased to a maximum value. The maximum hit rate value, .85 , as shown in Table IV, corresponds to an LRS raw score of 12 or more. Thus, the LRS raw score value 12 represents the optimal cut-off point. Subjects from this study receiving a score of 12 or more had an 88 percent chance of belonging to the lithium response group; subjects with a score of 11 or less had a 76 percent chance of belonging to the lithium nonresponse group; taken together, this yields a total hit rate of 85 percent.

The number of days from admission to completion of MMPI testing ranged from zero to 109 days. The number of days from admission to the beginning of lithium treatment ranged from zero to 199 days with an average of 18 days. One hundred fifty subjects began lithium treatment within 31 days of admission and 29 subjects after 31 days. Subjects completed the MMPI at some time during their hospitalization ranging from 196 days before lithium treatment to 60 days after the onset of lithium treatment. Ninety-seven subjects completed the MMPI prior to the onset of lithium treatment. Forty-two subjects completed the MMPI within ten days after the onset of lithium treatment. Forty subjects completed the MMPI 11 or more days after the onset of lithium treatment. Lithium takes approximately ten days to produce beneficial effects. Because 40 subjects completed the MMPI within 11 to 60 days following the initiation of lithium treatment, this may have altered their MMPI scores, including scores on the LRS. To determine if MMPI scores were altered significantly, a standard one-way analysis of variance was utilized to compare elapsed time in days between MMPI testing and 
initiation of lithium. One hundred thirty-nine responders and nonresponders who completed the MMPI ten or less days prior to beginning lithium treatment were compared with 40 responders and nonresponders who completed the MMPI 11 or more days after beginning lithium treatment. As seen in Table $V$, there was not a significant difference between the two groups.

TABLE V

COMPARING LRS SCORES TO ELAPSED TIME IN DAYS BETWEEN MMPI TESTING AND INITIATION OF LITHIUM

\section{LITHIUM RESPONDERS}

Source

tested ten or less days

prior to 1 ithium $(n=105)$
Standard

Mean Deviation

$17.37 \quad 14.4$
F $\quad$ Sig.

$.001 \cdot$ N.S.

tested eleven or more days

after lithium $(n=25) \quad 17.61 \quad 10.57$

\section{LITHIUM NONRESPONDERS}

tested ten or less days

prior to lithium $(n=34) \quad 12.47 \quad 17.77$

$.009 \quad$ N.S.

tested eleven or more days

after lithium $(n=15) \quad 11.73 \quad 13.07$

All subjects in this research were likely to have exhibited symptoms of mania and/or schizophrenia during their hospitalization. MMPI clinical scales 8 and 9 measure schizophrenia and mania respectively. To determine the utility and the uniqueness of the LRS, analyses were conducted utilizing $K$ corrected and noncorrected raw 
scores of the MMPI clinical scales 8 and 9. One analysis utilized was the Kuder Richardson Formula 21, assessing reliability for each of the four scales. Scales 8 and $8+1 K$ were found to have Kuder Richardson reliability coefficients of .91 and .77 respectively. Scales 9 and $9+.2 \mathrm{~K}$ had reliability coefficients of .71 and .61 .

To measure the ability of these four scales to discriminate responders from nonresponders, a standard one-way analysis of variance was utilized. As shown in Table VI, only scale $8+1 \mathrm{~K}$ significantly separated responders from nonresponders, $\underline{F}(1,178)=5.24, \underline{p}<.025$. However, it must be noted that as presented in Table III, the LRS indicated a far greater degree of separation between these two groups, $F$ $(1,178)=66.35, \underline{p}<.001$. These findings require further replication. 
TABLE VI

ANALYSIS OF VARIANCE OF SCORES ON

FOUR MMPI CLINICAL SCALES

MMPI CLINICAL SCALE 8

\begin{tabular}{|c|c|c|c|c|}
\hline Source & Mean & $\begin{array}{l}\text { Standard } \\
\text { Deviation }\end{array}$ & $\underline{F}$ & $\underline{p}$ \\
\hline responders $(n=130)$ & 24.1 & 12.7 & & \\
\hline nonresponders $(n=49)$ & 26.8 & 13.2 & 1.61 & N.S. \\
\hline \multicolumn{5}{|c|}{ MMP I CLINICAL SCALE $8+1 \mathrm{~K}$} \\
\hline responders $(n=130)$ & 35.5 & 9.6 & & \\
\hline nonresponders $(n=49)$ & 39.4 & 10.5 & 5.34 & .025 \\
\hline \multicolumn{5}{|l|}{ MMPI CLINICAL SCALE 9} \\
\hline responders $(n=130)$ & 24.3 & 6.3 & & \\
\hline nonresponders $(n=49)$ & 22.4 & 5.6 & 3.6 & N.S. \\
\hline \multicolumn{5}{|c|}{ MMPI CLINICAL SCALE $9+.2 \mathrm{~K}$} \\
\hline \multirow[t]{2}{*}{ responders $(n=130)$} & 26.6 & 5.9 & & \\
\hline & & & 3.30 & N.S. \\
\hline nonresponders $(n=49)$ & 24.9 & 5.1 & & \\
\hline
\end{tabular}


A Pearson Product-Moment Correlation Coefficient was utilized to measure the relationship between the four MMPI clinical scales and the LRS. Results (Table VII) show a significant negative correlation among the LRS and scale $8+1 K$. The LRS is indicative of manic-depression and is negatively correlated to the measure of schizophrenia. A significant positive correlation was calculated among the LRS and scale $9+.2 K$. A probable cause for this is that lithium responders exhibit symptoms of hypomania which is what scale $9+.2 \mathrm{~K}$ estimates.

TABLE VII

PEARSON PRODUCT-MOMENT CORRELATION COEFFICIENTS

AMONG THE LRS AND THE MMPI CLINICAL SCALES *

LRS AND THE

MMPI CLINICAL SCALE

8

$8+1 k$

9

$9+.2 k$

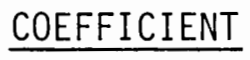

$-.12$

$-.21$

.49

.50

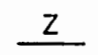

$-1.6$

$-2.8$

6.5

6.7

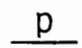

N.S. .01 .001 .001

A11 calculations based on 179 subjects.

Past studies have suggested that many patients with a manic-depressive illness are not correctly diagnosed as such. This research compared the admitting and discharge diagnoses of the subjects utilized in this study. Admission and discharge diagnoses for the lithium responders and nonresponders are listed on Table VIII. Thirty-six percent of the responders were diagnosed manic-depressive at admissions and almost twice as many were diagnosed as manic-depressive when discharged. The difference between admitting and discharge 
diagnoses was significant, $\underline{z}=-5.49, \underline{p}<.001$. Conversely, of those responders diagnosed schizophrenic at admission, approximately half were not so diagnosed when discharged. The difference between these diagnoses was also significant, $\underline{z}=4.30, \underline{p}<.001$. Similar significant differences were measured when the responders and nonresponders were combined. There was no significant difference between admission and discharge diagnoses of the nonresponder group. 


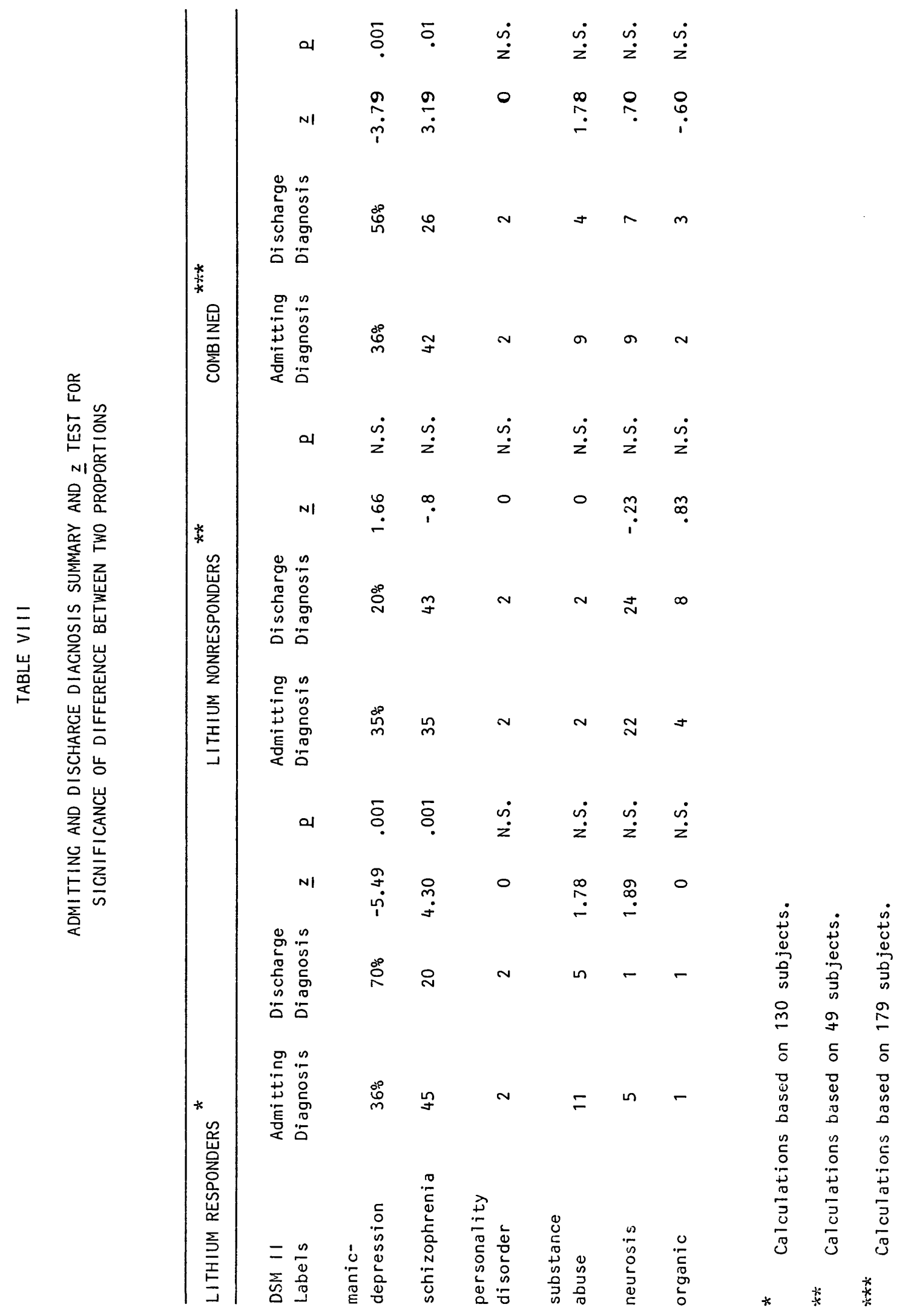




\section{CHAPTER VI}

\section{DISCUSSION}

Lack of objective measures to separate schizophrenia from mania has created confusion in the prescribing of psychotropic medications. The manic-depressive patient requiring lithium treatment, but treated incorrectly with a major tranquilizer is possibly exposed to side effects such as the extrapyramidal syndrome and drowsiness. The manic-depressive symptoms are not treated, but prolonged until the correct treatment is ascertained and prescribed. The schizophrenic patient requiring major tranquilizers, but incorrectly treated with lithium is exposed to the dangers of lithium toxicity and possible side effects. Inefficacious neuroleptic treatment is the result of inaccurate assessment and diagnosis. A diagnosis is rarely changed until the patient is discharged. Since the initial diagnosis may dictate the choice of treatment, a manic-depressive patient diagnosed as a schizophrenic may be overlooked as a lithium responder.

Subjects in the present study, on the average, were not prescribed lithium until the 18th day of hospitalization. This suggests that subjects were denied the most efficacious treatment for over 2.5 weeks. Diagnoses of manic-depression increased significantly from admissions to discharge. At discharge, 20 percent or approximately 36 more subjects were diagnosed as suffering from manic-depression. The reason for the increase in manic-depressive diagnoses is likely due to the efficacy of lithium treatment. This trend is consistent with past research findings 
by Baldessarini (1970) and Abrams et al. (1976). The diagnostic trends this research reports suggest that some of the patients in this study were incorrectly diagnosed during admission. This incorrect diagnosis may have interfered with their being prescribed the most efficacious medication. With the increase of efficacious and specific pharmacological treatments, it is important to prescribe medication accurately. Diagnoses play an important role in the medication choice, yet it has been shown that manic-depressive patients have been diagnosed incorrectly. Thus, many patients who may benefit from lithium may be denied lithium and may be treated with a major tranquilizer instead. These patients who are not receiving lithium may be exposed to the serious side effects associated with the major tranquilizers and probably will not profit from taking these drugs. Prescribing lithium would be improved if a test was developed which could identify those patients who would respond to lithium treatment. Past researchers have been unable to develop such a reliable test. The MMPI scale developed by this research significantly differentiated patients who responded to lithium from patients who did not respond to lithium.

The MMPI scale developed by this research selected MMPI items that were significantly related to lithium responders according to their chi-square values. Two lithium response scales were developed from this item analysis. One scale consisted of 19 items and the other scale consisted of 25 items. The larger scale included the 19 items of the smaller scale and six additional items. These six additional items were added as a result of less stringent selection criteria. The scale composed of the 25 items discriminated between lithium responders and lithium nonresponders with greater significance when compared to the 
smaller item scale. The larger MMPI item scale was referred to as the Lithium Response Scale (LRS).

The purpose of the LRS is to predict 1ithium response. A cut-off score is required to determine the maximum number of LRS items to predict lithium response. Lithium response scores from this research were utilized for developing this optimum cut-off value. Each subject could have responded to a maximum of 251 ithium response items. Hit rate proportions were measured for the LRS score values. Subjects receiving a scale score value of 12 were found to have an 88 percent chance of belonging to the lithium response group. The LRS score value 12 was found to be the optimum cut-off value for the LRS.

This study was unable to implement experimental control of the time between completing the MMPI and beginning lithium treatment. Several subjects in this research were administered the MMPI before the tenth day of lithium treatment and others after the tenth day of treatment. Lithium has been found to produce desirable effects within ten days. It is possible that the lithium may have affected subject's responses on the MMPI. This is why, in Table V, subjects who were treated with lithium ten or less days prior to the completion of the MMPI testing were compared with subjects who were treated with lithium 11 or more days after completion of the MMPI. There was no significant difference between the two groups. Even though this research is not a controlled study, the aforementioned statistical analysis indicates that the difference of subject's responses associated with elapsed time in days between MMPI testing and initiation of lithium is negligible.

The LRS is a unique MMPI scale measuring response to lithium. The LRS was compared to MMPI clinical scales 8 and 9 . These scales were 
utilized because past research has shown that manic-depressive individuals exhibit symptoms of mania and schizophrenia (Murphy et al., 1975, Carpenter et a1., 1973, and Procci, 1976). Only the MMPI clinical scale $8+1 K$ was found to significantly separate lithium responders from Tithium nonresponders reliably. Previous research from Ananth et al. (1980) and Steinbook and Chapman (1970) had found the MMPI clinical scales, including scale 8 not significantly related to lithium response. There may be several reasons for the present research reporting significance where other research reported no significance. One possible explanation may be due to the difference of selection criteria for responders and nonresponders. Another explanation may be that the present study's positive correlation of scale 8 may be due to chance alone.

Evidence from this research suggests that the LRS is negatively correlated to schizophrenia and positively correlated to hypomania. This further establishes the scale's validity to predict lithium response. Results from the analysis of variance, Kuder-Richardson analysis and measurements of correlation indicate that the LRS has promise in identifying individuals who may benefit from 1 ithium treatment.

Two treatment groups were utilized in this study. One group was comprised of lithium responders and the other 1 ithium nonresponders. Since the selection of subjects did not control for mood and affect, each treatment group included subjects who exhibited symptoms of depression, mania and/or schizophrenia. Though this study did not control for mood and affect, past researchers have often discriminated between mania and depression when attempting to predict lithium 
response. Donnelly et al. (1978) developed a scale for predicting lithium response, limited to subjects exhibiting symptoms of depression. To select subjects exhibiting symptoms of depression, subjective judgment from clinicians was utilized. The present study is unique compared to the Donnelly et al. (1978) study because subjects herein were not selected according to the symptoms they exhibited. Selection of subjects was based solely upon an objective criterion, subjects' response or nonresponse to lithium. The lithium response scale developed by Donnelly et al. (1978) was limited to predicting response to lithium in patients exhibiting symptoms of depression. The present LRS was not based upon the subjects' symptoms nor was it limited to measuring response to lithium with only subjects exhibiting symptoms of depression.

The present study is encumbered with several design weaknesses. One weakness was the post hoc design. Subjects were selected for study after they were treated rather than random assignment to treatment groups at the beginning of hospitalization. Another weakness was the selected sample. Many patients who received treatment at Dammasch did so because of the geographical location and they were unable to afford a private psychiatric hospital. Because of the post hoc design and selected sample, further research is necessary to measure the reliability and predictive validity of the LRS. Future research should include cross validation among several treatment settings. To do so, several psychiatric hospitals, both private and public, in various geographical locations should be utilized. Subjects should be selected during the admission screening. All subjects exhibiting psychotic symptoms would be selected for research. Most subjects exhibiting 
psychotic symptoms will require treatment with 1 ithium and or major tranquilizers. All subjects would be administered the MMPI prior to being prescribed lithium. Subjects would then be randomly assigned to two groups, Group A and Group B. Subjects in Group A would be prescribed lithium at the beginning of their hospitalization based on their LRS scores. The physician may elect to continue or discontinue lithium treatment during the course of hospitalization. Subjects in Group B would be prescribed lithium based upon the physician's clinical judgment. The MMPI scores would not be revealed to the physicians in Group B. It is hypothesized that at the beginning of hospitalization, Group A will have a significantly higher number of subjects prescribed lithium than Group B. It is also hypothesized that, in Group A, the number of subjects prescribed lithium at the beginning of hospitalization compared to the number of subjects discharged with lithium will not be significantly different. It is assumed that all physicians are highly competent and during the course of hospitalization will correctly identify those subjects who should have been prescribed lithium and were not prescribed lithium at the beginning of hospitalization. Therefore, it is hypothesized that for Group B, the number of subjects prescribed lithium at the beginning of hospitalization compared to the number of subjects discharged with lithium will be significantly different. If the hypotheses are accurate, then the proposed study will show that the LRS correctly identifies lithium responders at the beginning of hospitalization. The LRS this research has developed was not designed to diagnose, but to predict lithium response. The LRS has shown potential as an effective tool for predicting lithium response. 
A variety of clinical implications would arise if further research was to document the effectiveness of the LRS as a tool for predicting lithium response. The effect the LRS would have on the clinical arena would be both positive and negative. The negative effects would result from clinicians making a type I or type II error. A type I error would be refusing to prescribe lithium to a patient who required lithium, but tested as a lithium nonresponder. The LRS was designed to predict lithium response not to predict refractoriness to lithium. Therefore, clinicians should be careful not to utilize the LRS as a predictor of lithium nonresponse. If a patient was tested as a nonresponder, then other criteria should be applied to consider the prescribing of lithium. A type II error would be to prescribe lithium to a patient who does not require lithium, but tested as a responder. Type II subjects in the present research were probably prescribed 1ithium because they exhibited symptoms related to manic-depressive patients. These subjects did not respond to lithium and the physician discontinued lithium treatment. Another problem the LRS may have is the difficulty of administering the MMPI to agitated psychotic patients. It would help if only the 25 LRS items were administered rather than the 566 MMPI items. Further research would be needed to determine if the LRS is effective when extracted from the full MMPI.

On speculating that further documentation would find the LRS as an effective tool, then the positive clinical effects of the LRS would be profound. Patients admitted to a psychiatric hospital could be diagnosed as lithium responders in less time. Therefore, weeks of observation that may have been necessary for predicting lithium response could be reduced to a few days because of the information obtained from 
the LRS. It is also possible that psychiatric outpatient clinics could utilize this scale. Patients attending outpatient clinics could be diagnosed as lithium responders, thus alleviating the need for the patient to undergo hospitalization. Outpatient clinics are likely to be comprised of patients exhibiting less agitated symptoms than patients in a hospital setting. Therefore, lithium response scores could possibly be lower for responders and nonresponders. Lower scores would increase the difficulty of discriminating lithium responders from lithium nonresponders. In an outpatient setting, it is possible that the base rate of lithium responders is lower than the base rate of responders in the hospital. A lower proportion of lithium responders attending an outpatient clinic would increase the chances of making a type I error. Further research is necessary to determine the cut-off score and predictive validity of the LRS in an outpatient setting. The LRS shows potential as an effective instrument for predicting lithium response. In the past, clinicians have had to use subjective judgment for assessing patients' potential for responding to lithium. The LRS, as an effective instrument, would be an objective criterion among several subjective criteria for predicting lithium response. Patients who were once overlooked as lithium responders would be identified expediently through the use of the LRS. Once documented as an effective tool for predicting lithium response, the LRS would benefit both clinicians and patients. 


\section{REFERENCES}

Abrams, R., Taylor, M. A. \& Gaztanaga, P. Manic-depressive 171 ness and paranoid schizophrenia. Archives of General Psychiatry, 1974, 31, 640-642.

AMA Drug Evaluations. Chicago: American Medical Association, 1980.

Ananth, J., Engelsmann, F., \& Kiriakos, R. Evaluation of 1ithium response. Canadian Journal of Psychiatry, 1980, 25, 151-154.

Baastrup, P. C., \& Schou, M. Lithium as a prophylactic agent against recurrent depression and manic-depressive psychosis. Archives of General Psychiatry, 1967, 16, 162-172.

Baastrup, P. C., \& Schou, M. Prophylactic 1ithium. Lancet, 1968, $1: 7557,1419-1422$.

Baldessarini, R. J., \& Lipinski, J. F. Lithium salts: 1970-1975. In D. F. Klein \& R. Gittelman-Klein (eds), Progress in Psychiatric Drug Treatment (vol. 1). New York: Brunner/Mazel, 1976.

Boston Collaborative Drug Surveillance Program. Drug-induced extrapyramidal symptoms. Journal of the American Medical Association, $1973,224,889-891$.

Burdick, B. M., \& Holmes, C. B. Use of the lithium response scale with an outpatient psychiatric sample. Psychological Reports, 1980, 41:1, 69-70.

Cade, J. F. Lithium salts in the treatment of psychotic excitement. Medical Journal of Australia, 1949, 2, 349-352.

Carlson, G. A., \& Goodwin, F. K. The stages of mania. Archives of General Psychiatry, 1973, 28, 221-228.

Carpenter, W. T., Jr., \& Straus, J. S. Are there pathognomic symptoms in schizophrenia: An emperic investigation of Schneider's first-rank symptoms. Archives of General Psychiatry, 1973, 28, 847-853.

Chaplin, J. P. Dictionary of Psychiatry (New Rev. ed.). New York: Dell Publishing Co., Inc., 1975.

City stops the sale of salt substitute. The New York Times, February 20,1949 , p. 53 . 
Clopton, J. R. MMPI scale development methodology. Journal of Personal ity Assessment, 1978, 42:2, 148-151.

Cohen, R. A. Manic-depressive illness. In A. M. Freedmond \& H. I. Kaplan (eds.) Comprehensive Text Book of Psychiatry (Vol. 1), Baltimore: WaverTy Press, 1975.

Corcoran, A. C., Taylor, R. D., \& Page, I. H. Lithium poisoning from the use of salt substitute. Journal of the American Medical Association, $1949, \underline{139}, 685-688$.

Dally, P. General introduction: historical development. Chemotherapy of Psychiatric Disorders, London: Plenum Press, 1967.

Davis, J. M. Overview: Maintenance therapy in psychiatry: II. affective disorders. American Journal of Psychiatry, 1976, 133:1, $1-13$.

Donnelly, E. F., Goodwin, F. K., Waldman, I. S., \& Murphy, D. L. Prediction of antidepressant responses to 1ithium. American Journal of Psychiatry, 1978, 135:5, 552-556.

Gattozzi, A. A. Lithium in the treatment of mood disorders. (Hew National Clearing House for Mental Health Information Publication No. 5033). Washington, D. C.: U. S. Government Printing Office, 1970 .

Hanlon, L. W., Romaine, M. III, Gilroy, F. J., \& Dietrick, J. E. Lithium chloride as a substitute for sodium chloride in the diet. Journal of the American Medical Association, 1949, 139, 688-692.

Holliday, A. R. A review of psychopharmacology. In B. B. Wolman (Ed.), Handbook of Clinical Psychology, New York: McGraw-Hill Book Co. 1965.

House, K. M. \& Martin, R. L. MMPI delineation of a subgroup of depressed patients refractory to lithium carbonate therapy. American Journal of Psychiatry, 1975, 132:6, 563-573.

Jefferson, J. W. \& Greist, J. H. Primer of Lithium Therapy. Baltimore: Waverly Press, Inc., 1977.

Johnson, G., Gershon, S., \& Hekimian, L. J. Controlled evaluation of lithium and chlorpramazine in the treatment of manic states: an interim report. Comprehensive Psychiatry, 1968, 9:6, 563-573.

Martin, E.W. \& Martin, R. D. Pitfalls of medication. In S. F. Alexander, D. J. Farage \& W. E. Hassan, Jr. (Eds.). Hazards of Medication, Philadelphia: J. B. Lippincott Co., 1971.

Matheson, D. W., Bruce, R. L., \& Beauchamp, K. L. The basic nature of research. Introduction to Experimental Psychology (2nd ed.). New York: Holt, Rinehart \& Winston, Inc., 1974. 
Murphy, D. F., Goodwin, F. K., \& Bunney, W. E. Jr. The psychobiology of mania. In D. A. Hamburg \& K. H. Brodic (Eds.), American Handbook of Psychiatry: New Psychiatric Frontiers (2nd ed.). New York: Basic Books, Inc., 1975.

Physician's Desk Reference (36th ed.). Orade11, N. J.: Medical Economics Co., Inc., 1982.

Procci, W. R. Schizo-affective psychosis: fact or fiction? Archives of General Psychiatry, 1976, 33, 1167-1178.

Raskin, D. E. Akasthisia: a side effect to be remembered. American Journal of Psychiatry, 1972, 123:2, 121-123.

Schlagenhauf, G., Tupin, J., \& White, R. B. The use of lithium carbonate in the treatment of manic psychosis. American Journal of Psychiatry, 1966, 123:2, 201-207.

Steinbook, R. M., Chapman, A. B. Lithium responders: an evaluation of psychological test characteristics. Comprehensive Psychiatry, $1970,11: 6,524-530$.

Stern, R. L. Clinical notes, suggestions and new instruments: severe lithium poisoning with complete recovery. Journal of the American Medical Association, $1949, \underline{139}, 710-711$.

Stevens, C. F. The neuron. Scientific American, 1979, 241:3, 55-65.

Task Force on Lithium Therapy. The current status of lithium therapy: report of the APA Task Force. American Journal of Psychiatry, 1975, 132, 997-1001. 


\section{APPENDIX A \\ NUMBER OF SUBJECTS RESPONDING TO \\ EACH INDIVIDUAL LLRS SCORE}

INDIVIDUAL LRS

SCALE SCORE VALUE

4
5
6
7
8
9
10
11
12
13
14
15
16
17
18
19
20
21
22
23
24

NUMBER OF
RESPONDERS
NUMBER OF

NONRESPONDERS
0

0

0

0

0

1

3

6

4

8

12

9

5

17

6

12

15

13

11

7
2

0

0

5

2

4

5

4

10

0

5

1

4

1

1

1

1

2

1

0

0

*

Calculations based on 130 subjects.

**

Calculations based on 49 subjects. 


\section{DAMMASCH STATE HOSPITAL}

WILSONVILLE, OREGON 97070 PHONE 682-3111

APPENDIX B
VISITING HOURS: 2:00 to 4:00 PM and 7:00 to 8:30 PM

WEEKENDS AND HOLIDAYS: 2:00 to 5:00 PM and 6:00 to 8:30 PM

October 20,1980

Mr. Neal Hayden

Dear Mr. Hayden:

This letter is in regard to your proposed research project concerning the development of an MMPI Scale for the prediction of therapeutic response to Lithium Carbonate.

The Research Committee, at this hospital, has reviewed your proposal and find that it meets the research criteria and does not violate patient confidentiality and respects human rights. They recommend that approval for this project be granted.

Having reviewed your proposal, I concur in the recommendation of the Research Committee and approval is hereby granted for you to conduct the research on the records at the Dammasch State Hospital.

This appears to be an innovative approach to predicting outcome and should be of great value if your supposition is correct. Good Luck!

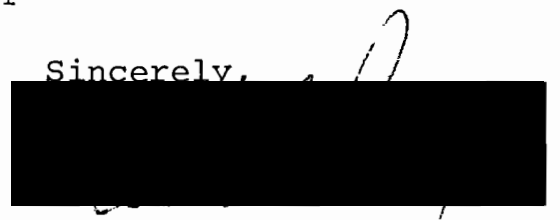

V. M. Holm, M.D. , Clinical Director

vmh/ew 